\title{
Herb-drug interactions
} between the medicinal mushrooms Lingzhi and Yunzhi and cytotoxic anticancer drugs: a systematic review

\author{
Chun Sing Lam', Lok Pui Cheng ${ }^{1}$, Li Min Zhou ${ }^{2}$ Yin Ting Cheung ${ }^{1}$ and Zhong Zuo ${ }^{{ }^{*}}$
}

\begin{abstract}
Background: Lingzhi and Yunzhi are medicinal mushrooms commonly used with cytotoxic chemotherapy in cancer patients in Asian countries. The current systematic review aims to identify potential pharmacokinetic or pharmacodynamic interactions from the existing literature to ensure their effective and safe combination usage in cancer patients.

Methods: A systematic search was conducted on nine major Chinese and English databases, including China Journal Net, Allied and Complementary Medicine Database, and Ovid MEDLINE ${ }^{\circledR}$, etc., to identify clinical, animal, and in-vitro studies that evaluate the effect of combined use of Lingzhi or Yunzhi with cytotoxic drugs. The Jadad scale was used to assess the quality of clinical studies.

Results: This search identified 213 studies, including 77 clinical studies that reported on the combined use of cytotoxic drugs with Yunzhi $(n=56)$ or Lingzhi $(n=21)$. Majority of these clinical studies demonstrated modest methodological quality. In clinical practice, the most commonly used cytotoxic drugs with Lingzhi were cisplatin, 5-fluorouracil (5-FU) and paclitaxel, whereas Tegafur/uracil (UFT)/Tegafur, 5-FU, and mitomycin were the ones used more often with Yunzhi. Only two clinical pharmacokinetic studies were available showing no significant interactions between Polysaccharide K (PSK) and Tegafur. From the pharmacodynamic interactions perspective, combination uses of Yunzhi/Lingzhi with cytotoxic drugs in clinical practice could lead to improvement in survival $(n=31)$ and quality of life $(n=17)$, reduction in tumor lesions $(n=22)$, immune modulation $(n=38)$, and alleviation of chemotherapy-related side effects $(n=14)$ with no reported adverse effects.
\end{abstract}

Conclusion: Our findings suggest that the clinical combination use of Lingzhi or Yunzhi with cytotoxic drugs could enhance the efficacy and ameliorate the adverse effects of cytotoxic drugs, leading to improved quality of life in cancer patients. More high quality clinical studies including pharmacokinetic herb-drug interactions studies are warranted to verify these observations and mechanisms involved. Based on the high quality clinical data, pharmacoepidemiology methods and bioinformatics or data mining could be adopt for further identification of clinical meaningful herb-drug interactions in cancer therapies.

Keywords: Herb-drug interaction, Lingzhi, Yunzhi, Cytotoxic drugs, Anticancer drugs, Medicinal mushrooms

*Correspondence: joanzuo@cuhk.edu.hk

${ }^{1}$ School of Pharmacy, Faculty of Medicine, The Chinese University of Hong Kong, Shatin, N.T., Hong Kong, People's Republic of China Full list of author information is available at the end of the article

\section{Background}

Although chemotherapy and radiotherapy remain the mainstay of cancer treatment in developed countries, an increasing number of cancer patients are seeking benefits from complementary and alternative 
medicine. Surveys in the United States, Canada and Europe revealed that an average rate of $35 \%$ of cancer patients have utilized Chinese herbal medicine during their treatment [1]. Such prevalence of Chinese herbal medicine use in cancer patients from Asian countries is expected to be even higher [2, 3].

It is well-known that the concurrent use of Chinese and Western medicines can cause herb-drug interactions that lead to both beneficial and harmful health outcomes. To highlight, herb-drug interactions are not uncommon in cancer treatment and may affect the clinical efficacy or safety of the treatment. One study demonstrated that over half of the patients undergoing chemotherapy took herbal products, of whom $27 \%$ were found to be at risk of clinically significant interactions between chemotherapy drug and herbs. In another study, authors detected 120 possible herb-drug interactions in 149 patients who reported concurrent use of Chinese herbs with conventional anti-cancer drugs $[4,5]$. As most chemotherapy drugs have a narrow therapeutic index, there is an urging need for clinicians and scientists to address the potential herb-drug interactions in oncology practice.

Among Chinese herbs, medicinal mushrooms have been used for a long time during the cancer treatment. Lingzhi (Reishi or Mannentake in Japanese) and Yunzhi (commonly known as Turkey tail) are common medicinal mushrooms that are readily available in Asian countries. They are believed to possess medicinal properties to treat cancers or relieve cancer-related symptoms [6]. The two mushrooms both belong to the Polyporaceae family and have similar characteristics based on Traditional Chinese Medicine theory including flavour and nature [7]. Despite their popular use in cancer patients, there are limited reports on the clinical outcomes from their herb-drug interactions during anti-cancer treatment.

Although systematic reviews and meta-analysis of Lingzhi and Yunzhi as an adjunct for cancer treatment have been performed [8-10], these reviews mostly focused on clinical outcomes with no mechanistic explanations for the potential beneficial or harmful interactions. By gathering both clinical and preclinical studies of this subject matter, the current systematic review aimed to evaluate the effects of the co-administration of cytotoxic drugs with the medicinal mushrooms, Lingzhi and Yunzhi. Specifically, we will identify potential pharmacokinetic and pharmacodynamic interactions between these medicinal mushrooms and chemotherapy drugs and discuss the implications of these interactions on the efficacy and safety of cancer treatment.

\section{Methodology}

\section{Database search}

A comprehensive search was conducted on the following databases: China Journal Net (1915 to June 2020), Wanfang Database (1990 to June 2020), and Chinese Biomedical Literature Database (1878 to June 2020). English databases included Allied and Complementary Medicine (1985 to June 2020), Embase (1910 to June 2020), Ovid MEDLINE $^{\circledR}$ (1946 to June 2020), Ovid Nursing Database (1946 to June 2020), Ovid Emcare (1995 to June 2020), and Natural Medicines Comprehensive Database.

The combination of search terms included keywords for cytotoxic anticancer drugs and medicinal mushrooms as shown in Additional file 1: Table S1. The keywords used for cytotoxic drugs were based on the Hong Kong Hospital Authority Drug Formulary with no targeted therapy drugs included in the current review. In addition, chemoprotectants such as leucovorin and mesna were included in the current search. Besides the specific names of the cytotoxic drugs, general terms such as "cytotoxic drug" and "antineoplastic drug" were also included in the search to increase the coverage.

For the two medicinal mushrooms, Chinese name, English name, Pinyin and Latin name of them together with the names of their active ingredients were incorporated in the search. For Lingzhi, keywords for search included Reishi, Mannentake, Lingzhi, Ganoderma lucidum, Ganoderma sinense, Ganoderic acid, Polysaccharide, 靈芝, 靈 芝酸, and 多糖. For Yunzhi, Turkey Tail, Yunzhi, Coriolus versicolor, Trametes versicolor, Polyporus versicolor, Krestin (PSK), Polysaccharide, Polysaccharide peptide (PSP), 雲芝 and 多糖肽. General terms including "medicinal mushroom" was also utilized in the search for more comprehensive coverage.

\section{Inclusion criteria}

This review included clinical, animal and in-vitro studies that reported the concurrent use of any cytotoxic drug with the two medicinal mushroom(s). The name of drug used, dosage form and administration route should be specified. The mushroom(s) could exist in any formulation containing a raw or processed form of the mushroom(s) that included the extract of its (their) active phytochemical components. They could be used alone or with other herbs or ingredients in a composite formula. Clinical studies had to involve two groups of patients, a control group that received only the cytotoxic drug or the medicinal mushroom(s) (or the mushroom-containing herbal formula) and a co-administration group that received the cytotoxic drug together with the medicinal mushroom(s). If the control group also received medicinal mushrooms, there should be significant dosage 
differences of the mushrooms in the treatment group. The languages of the included articles were restricted to English, Chinese and Japanese.

\section{Assessing the quality of clinical studies}

The Jadad scale was used to assess the quality of the clinical studies. This is a 5-point scale evaluating randomization, blinding, and withdrawals or dropouts of the clinical trials [11].

\section{Results and discussion}

\section{Results of the database search}

Figure 1 summarizes the process of database searching and literature selection. The initial search identified 9712 studies. After screening their titles and abstracts, about 455 studies were included and subjected to further full-text inspection and verifications based on the inclusion criteria. In total, 213 studies were included in this review with 119 of them focused on Lingzhi, 93 of them on Yunzhi, and 1 on the combination of Lingzhi and Yunzhi. Other characteristics of the included studies including languages used, type of studies, type of the mushroom preparations, and country of the origin, type of cancer together with Jadad score of the included clinical studies were summarized in Additional file 1: Table $\mathrm{S} 2$ and distributions of the included cytotoxic drugs were shown Additional file 1: Figure S1. The detailed information on the 77 clinical studies and 137 preclinical studies were listed in Additional file 1: Tables S3, S4, respectively.

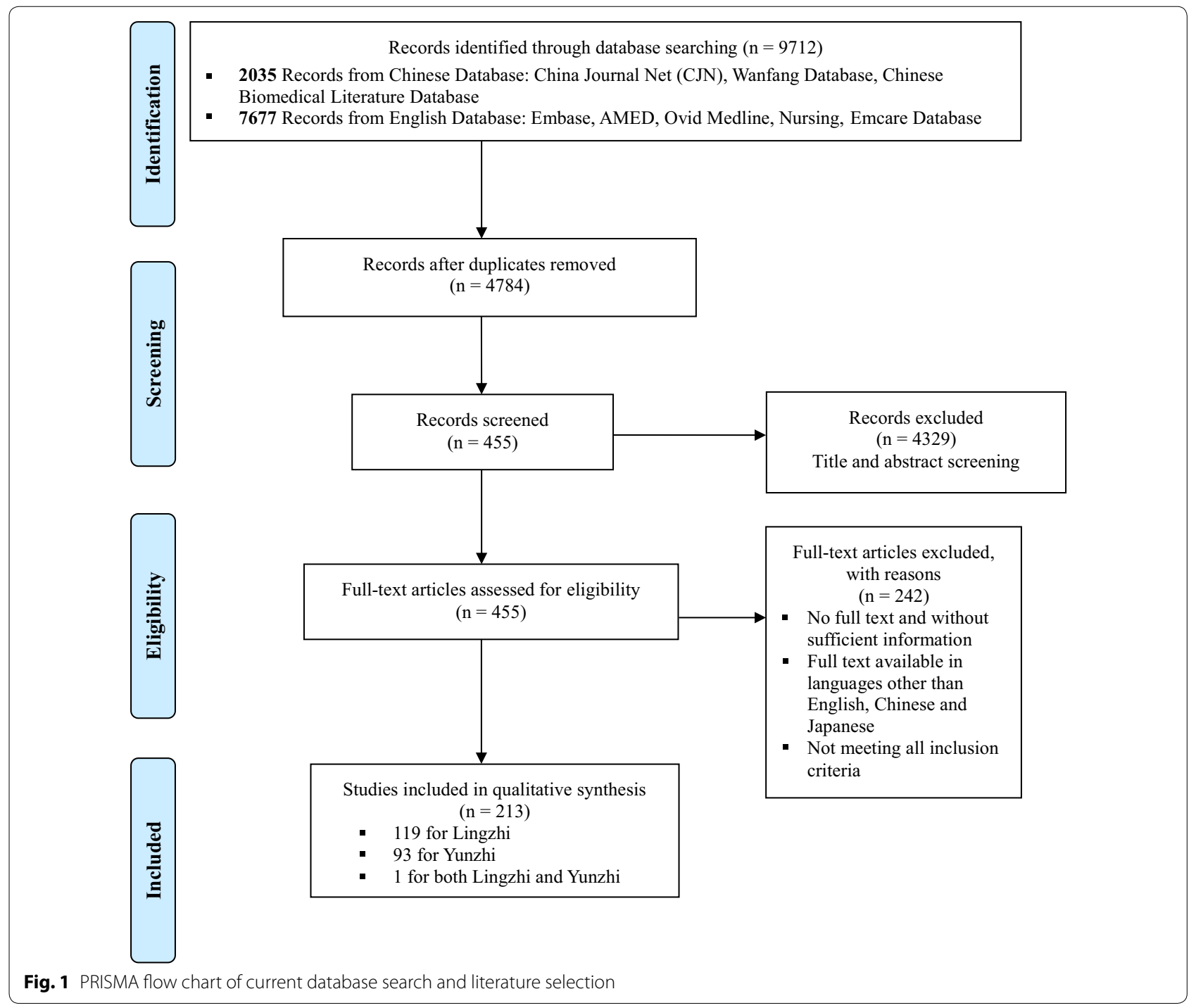




\section{Interaction outcome}

\section{Pharmacokinetic interactions}

In general, evidence on the pharmacokinetic interactions between Lingzhi or Yunzhi and cytotoxic drugs was scarce, except for the clinical pharmacokinetics interaction investigations between PSK and Tegafur as illustrated below.

Clinical studies on pharmacokinetic interaction Of all the 213 studies included in this review, only two studies evaluated the clinical pharmacokinetic interactions between cytotoxic drugs and medicinal mushrooms. Both studies evaluated the interactions between PSK (Yunzhi) and Tegafur (tetrahydrofuryl-5-fluorouracil), the prodrug of cytotoxic drug 5-FU. The conversion of Tegafur to 5-FU is mediated primarily by the CYP2A6 enzyme. Only small or non-significant changes in the blood level of 5 -FU and Tegafur was observed in most patients with up to 8-14 months PSK co-administration $[12,13]$.

Pre-clinical studies on pharmacokinetic interaction Only two in-vitro studies included in the review evaluated the pharmacokinetic interactions between Lingzhi and cytotoxic drugs. Ganoderic polysaccharides were shown to increase the distribution of doxorubicin in drug-resistant cancer cell lines, while Ganoderic acid B was shown to reverse the resistance of hepatocellular carcinoma toward doxorubicin, paclitaxel, and vincristine but not cisplatin $[14,15]$. Since doxorubicin, paclitaxel, and vincristine are substrates of P-glycoprotein, Lingzhi or its components were expected to modulate the P-gp mediated efflux of these cytotoxic drugs to increase their cell accumulation and reverse their resistance in the tumor cells [16].

For Yunzhi, consistent with clinical findings, an animal study showed that regardless of the administration route, PSK had no effect on the tissue level of 5-FU or its prodrug Tegafur in tumor-bearing mice [17]. In addition, another animal study showed that PSP could decrease cyclophosphamide clearance and increase the plasma half-life without affecting its distribution or protein binding. It was also found that a dose-dependent relationship existed between the systemic exposure of cyclophosphamide and acute rather than sub-chronic treatment with PSP [18].

\section{Pharmacodynamic interaction}

Tables 1 and 2 summarized the clinical and preclinical pharmacodynamic interactions between Lingzhi/Yunzhi and cytotoxic drugs, respectively. Outcomes on survival and quality of life, tumor inhibition and disease control rate, immune system and alleviation of the other adverse effects of cytotoxic drugs were further illustrated as follows.
Effect on survival and quality of life a. Clinical evidence Both Lingzhi and Yunzhi showed survival benefits in clinical studies. In this review, Yunzhi showed more clinical evidence than Lingzhi on increase in the survival rate and prolongation of the survival time. Among the 21 clinical studies on Lingzhi, only three studies measured survival outcomes with two of them reported increase in survival rate [19-21]. The survival rate increased when herbal formulae containing Lingzhi were used together with chemotherapy regimens (including 5-FU, cisplatin, doxorubicin, mitomycin, or vincristine). Notably, 37 of the 56 clinical studies on Yunzhi evaluated survival outcomes, 36 of which used PSK and one used Yunzhicontaining herbal formula. Twenty-nine of the 37 studies showed survival benefits of Yunzhi when co-administered with cytotoxic drugs. Among these Yunzhi-drug combinations, more evidence of survival benefits was reported for combinations with 5-FU, mitomycin, and UFT or Tegafur [22-50], whereas no survival benefits were reported for the combination with leucovorin [51]. Most of the Japanese studies on Yunzhi showed survival benefits of 3 or 5 years in gastric and colorectal cancers, leading to the approval of PSK approved as an adjunct in cancer treatment in Japan.

In terms of quality of life, Lingzhi co-administration with cytotoxic drugs has more clinical evidence than that for Yunzhi. Among the 21 included studies for Lingzhi, 12 of them measured the quality of life of cancer patients, and all of them observed an improvement by the coadministration of Lingzhi with 5-FU, capecitabine, cisplatin, gemcitabine, leucovorin, oxaliplatin, paclitaxel, and vinorelbine. The improvement in the quality of life was mostly observed in lung cancer patients ( 8 of the 12 studies) [21, 52-59]. Among the included studies, only 5 of the 56 clinical studies on Yunzhi measured the quality of life of cancer patients after the co-administration of Yunzhi with various cytotoxic drugs (5-FU, cisplatin, carboplatin, capecitabine, cyclophosphamide, doxorubicin, etoposide, mitomycin, oxaliplatin, paclitaxel and UFT) and all of them showed improvement [48, 49, 60-62].

Overall, more clinical evidence was reported on the survival benefits for the co-administration of chemotherapy with Yunzhi specifically PSK especially in gastric and colorectal cancer, whereas more evidence was reported on the improvement in the quality of life for the coadministration of chemotherapy with Lingzhi, especially in lung cancer patients.

\section{b. Preclinical evidence}

Animal studies on the concurrent use of Lingzhi or Yunzhi with cytotoxic drugs also measured the survival outcomes and substantiated the findings of the abovementioned clinical studies. With regard to Lingzhi, its survival benefits were also observed in animal studies 


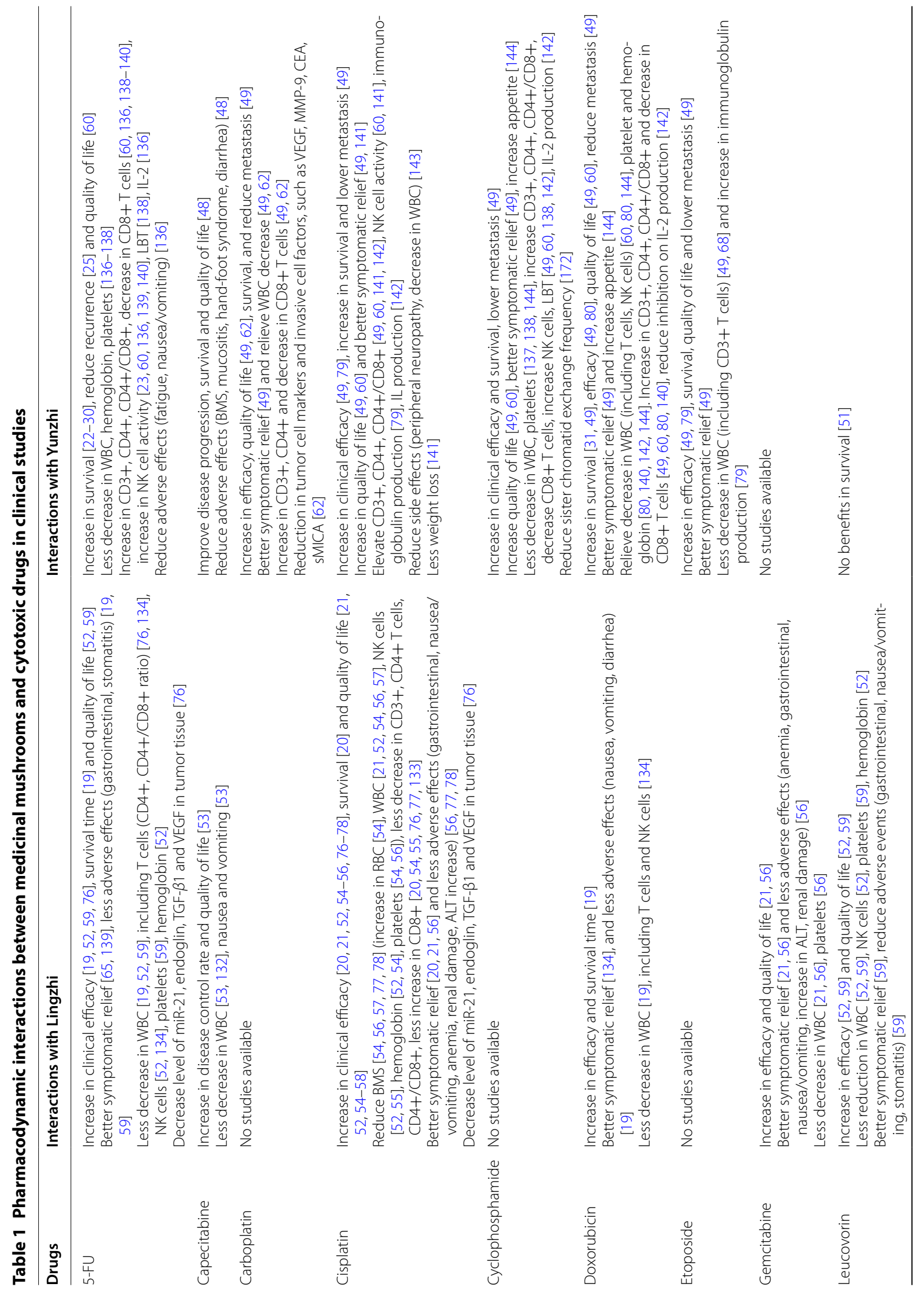




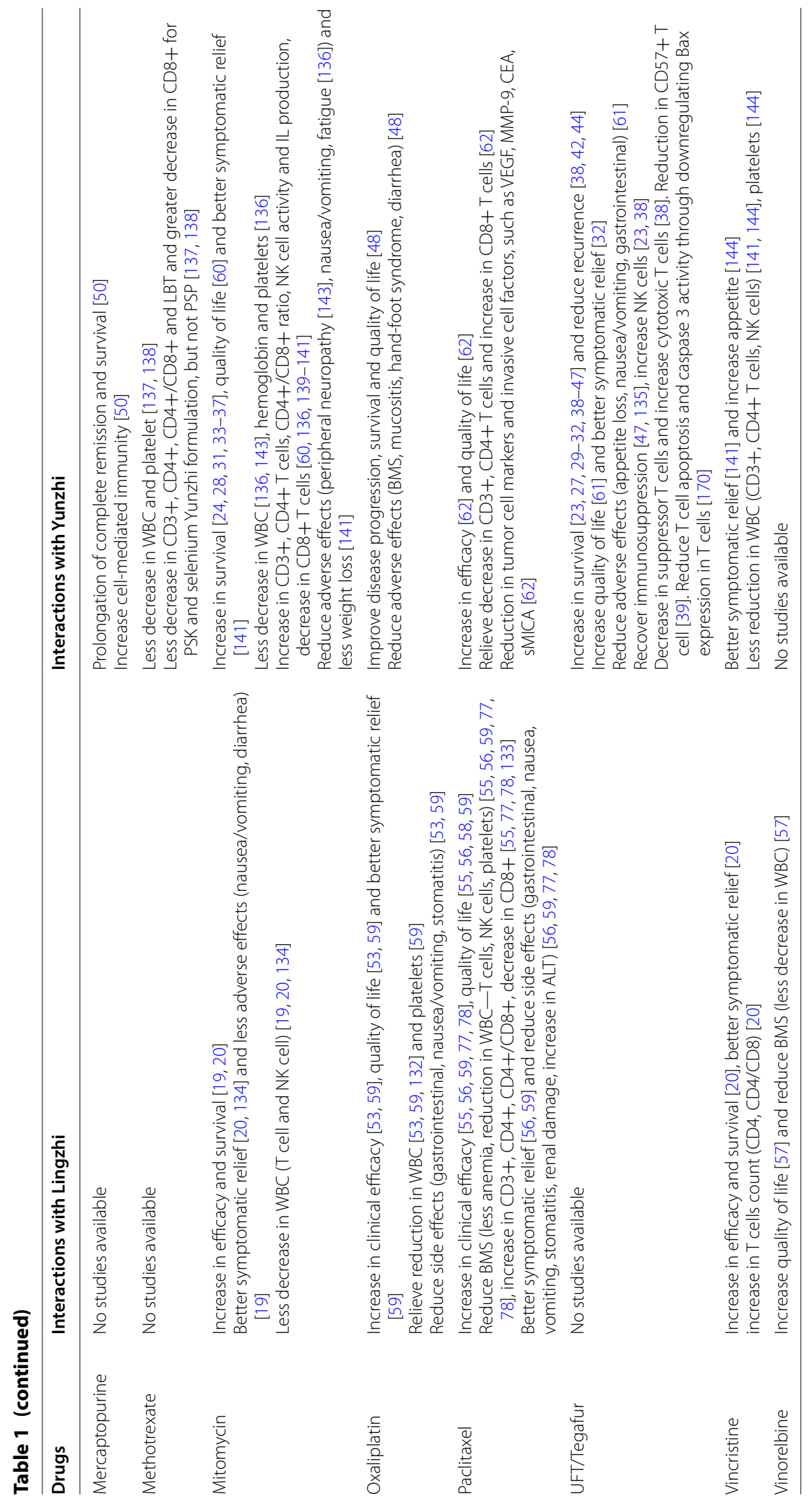




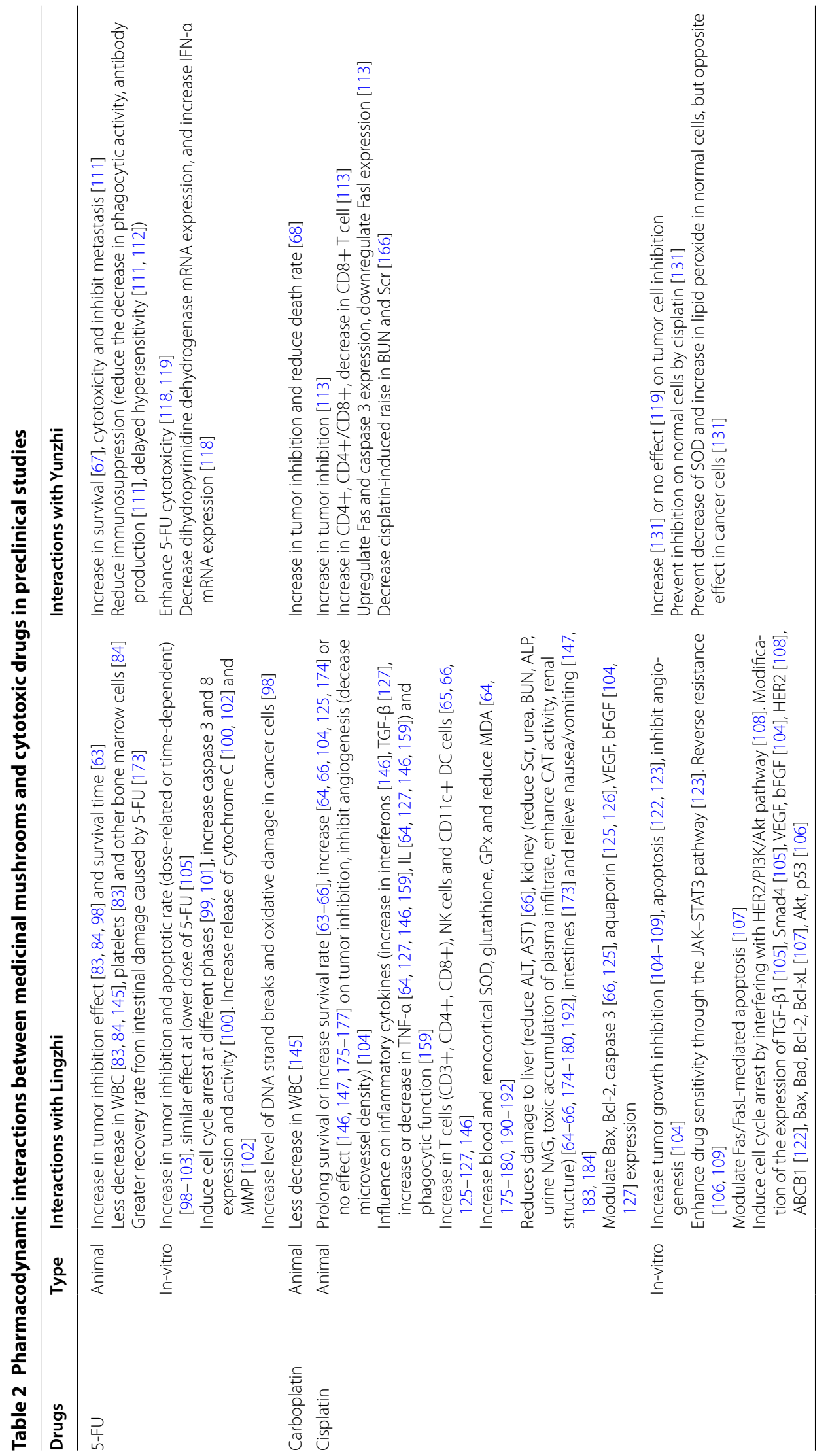



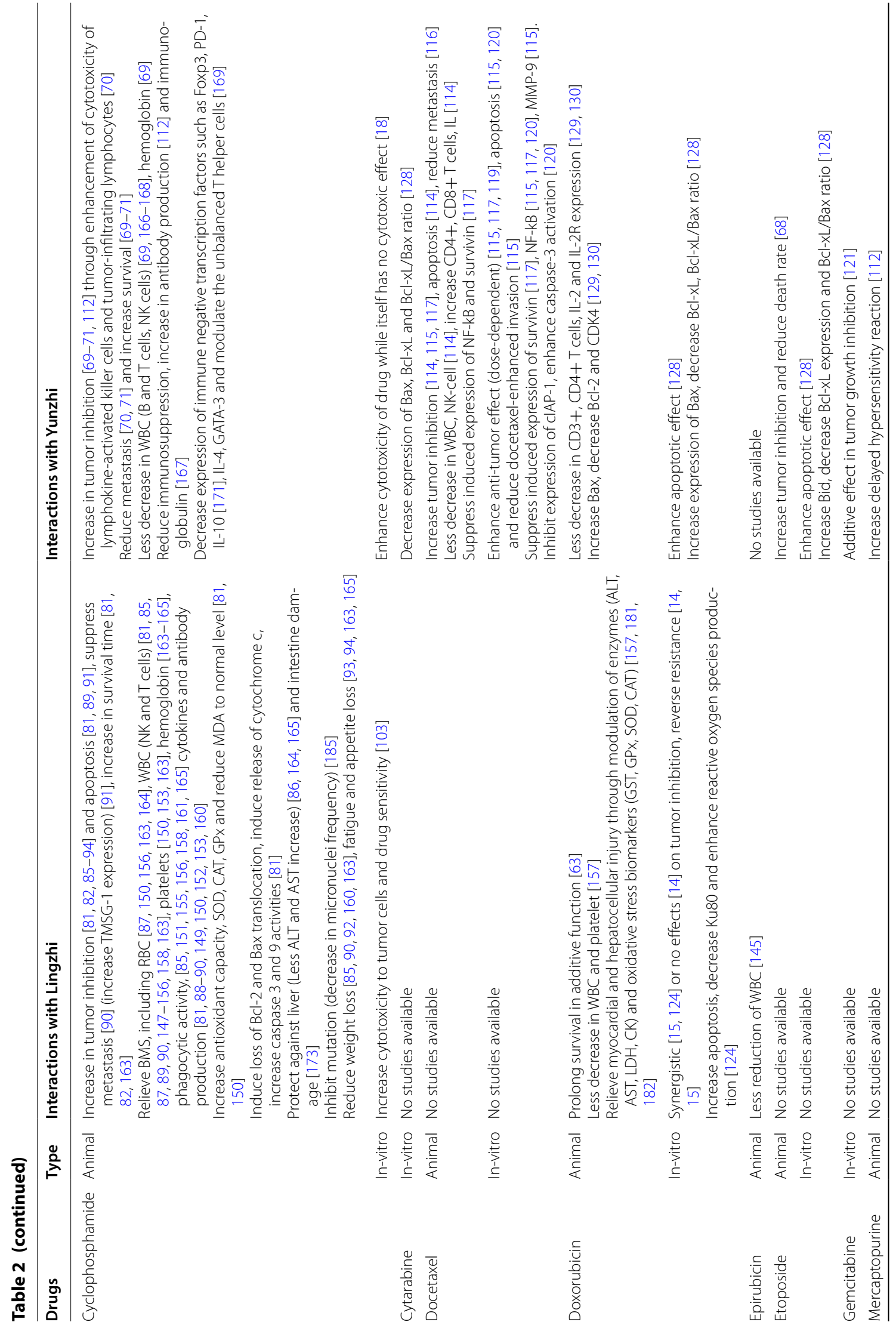


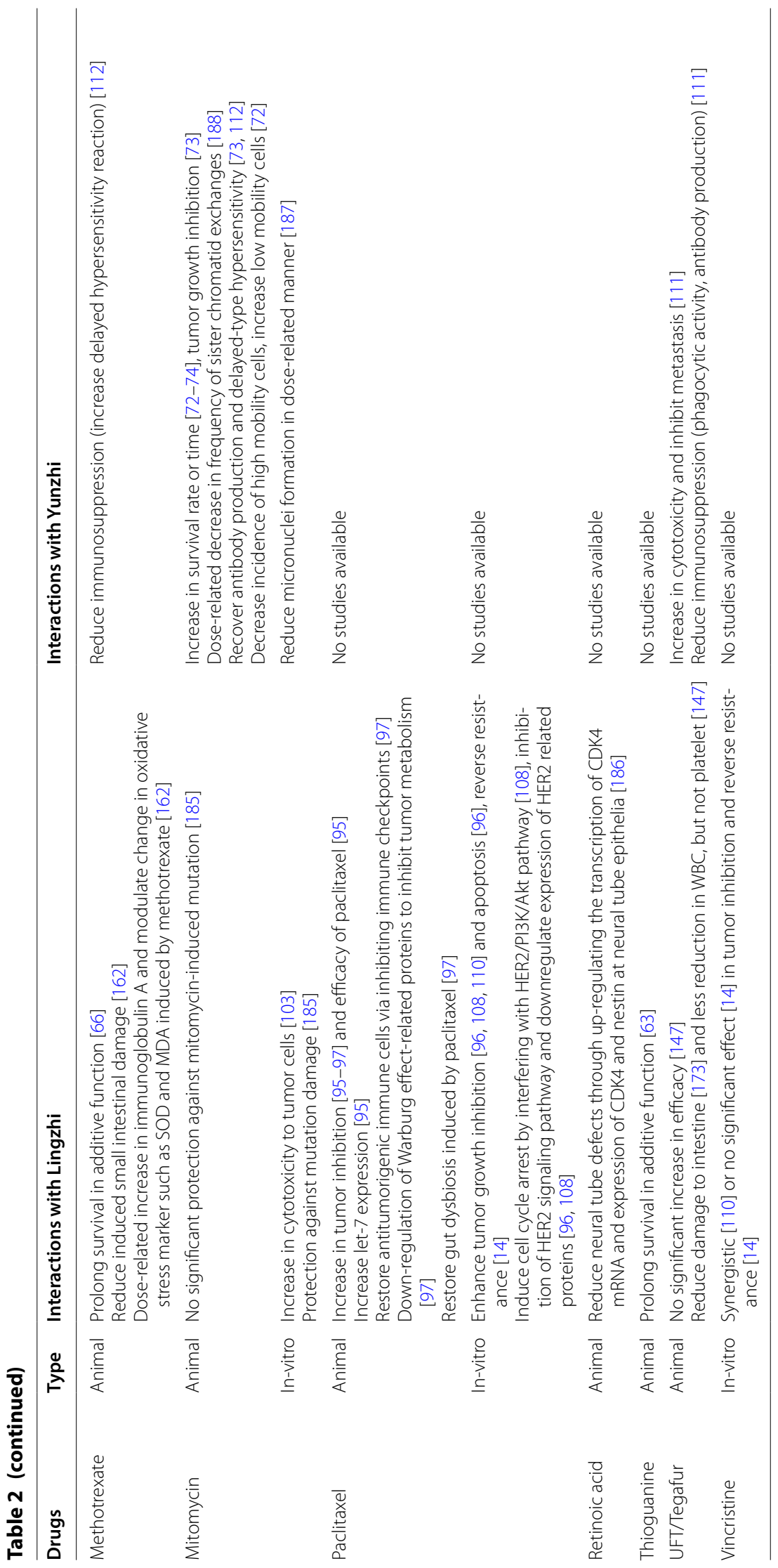


when co-administered with 5-FU, carboplatin, cisplatin, and doxorubicin which also shown benefits in clinical studies [63-66]. With regard to Yunzhi, the survival rate or time of animals increased when it was co-administered with 5-FU, cyclophosphamide, etoposide, and mitomycin, which were consistent with the findings from clinical studies [67-74].

Effect on tumor inhibition and disease control rate $a$ Clinical evidence

Most of the clinical studies identified in our review measured efficacy based on World Health Organization or the Response Evaluation Criteria in Solid Tumor (RECIST) [75]. The co-administration of Lingzhi with various cytotoxic drugs showed an increase in disease control rate or clinical efficacy via the reduction of tumor lesion size; these drugs include 5-FU, capecitabine, cisplatin, doxorubicin, gemcitabine, leucovorin, mitomycin, oxaliplatin, paclitaxel, and vincristine [19-21, 52-56, 59, 76-78]. In addition, co-administration of Lingzhi with 5-FU and cisplatin could further reduce the expressions of microRNA-21 (miR-21), endoglin, transforming growth factor (TGF)- $\beta$, and vascular endothelial growth factor (VEGF) [76].

The co-administration of Yunzhi with several cytotoxic drugs (carboplatin, capecitabine, cisplatin, cyclophosphamide, doxorubicin, etoposide, mercaptopurine, oxaliplatin and paclitaxel) showed increase in clinical efficacy $[49,62,79,80]$ and improvements in disease progression or control $[48,50]$. Some Yunzhi-drug combinations (5-FU, carboplatin, cisplatin, cyclophosphamide, doxorubicin, etoposide and UFT) also reduced tumor recurrence [25, 38, 42, 44] and metastasis [49]. Lower level of markers for tumor cell division, proliferation and invasion were found when paclitaxel and carboplatin were used with PSP [62].

Notably, most studies showed an enhancement in the cytotoxicity toward tumor cells when cytotoxic drug were used with these two medicinal mushrooms, suggesting no disadvantage for the addition of mushrooms in chemotherapy regimens.

\section{b. Preclinical and mechanistic evidence}

Our review revealed that the mechanisms of interactions between Lingzhi or Yunzhi and cytotoxic drugs involve multiple targets, including genes, proteins, and signaling pathways, to synergistically increase the tumor-inhibitory effect. Most animal studies support the clinical findings above. For Lingzhi, increase in the tumor inhibition rate was also demonstrated in animal studies [81-98] and in-vitro studies [96-110]. Some animal studies also observed suppression of metastasis by the co-administration of Lingzhi with cyclophosphamide [90, 91]. Regarding Yunzhi, enhancement of the antitumor effects of cytotoxic drugs and reduction in metastasis by Yunzhi have also been demonstrated in animal studies [68-71, 73, 111-117] and in-vitro studies $[18,115,117-121]$.

The effects of Lingzhi co-administered with cytotoxic drugs on tumor inhibition were multifaceted in both animal and in-vitro studies. Some combinations exert synergistic effect through induction of cell cycle arrest at different stages or increase the apoptotic rate $[81,89$, 91, 96, 99-102, 122-124]. In addition, the enhancement of the antitumor effect was shown to be achieved via the inhibition of tumor cell angiogenesis [104] or increase in the reactive oxygen species production [124]. Various invitro studies have shown that Lingzhi could enhance the tumor-inhibitory effect by reversing resistance to cytotoxic drugs [14-16]

Lingzhi co-administration with cytotoxic drugs affects different pathways and cancer targets. In animal and invitro studies, various pathways related to cell cycle arrest, apoptosis, and angiogenesis were affected, including the Janus kinase/signal transducer and activator of transcription 3 (JAK-STAT3), the protein kinase B (Akt) [106, 123] and the Human epidermal growth factor receptor 2 (HER2) signaling pathway [96, 108], eventually affecting the apoptotic molecules, for example, by altering B-cell lymphoma (Bcl) and Bcl-2-associated X (Bax) [66, 81, 125], caspase 3 and 8 activation [81, 100, 107, 125], and Fas and Fas Ligand (Fasl) [104]. The expression of other target genes or proteins was also affected, such as aquaporin $[125,126]$, VEGF and basic fibroblast growth factor (bFGF) [104, 127], and tumor metastasis suppressor gene 1 (TMSG-1) protein [91], all of which increased tumor inhibition. Notably, a recent study found that such synergistic effect may be due to the inhibition of tumor metabolism via down-regulating Warburg-related proteins and restoration of the gut dysbiosis induced by paclitaxel [97]. Regarding the increasing evidence of microbiota involvement in chemotherapy outcomes, it is worth looking into interactions with other cytotoxic drugs on gut microbiome level.

For Yunzhi, both PSK and PSP were reported to further enhance the apoptotic activity when co-administered with docetaxel, doxorubicin and etoposide $[114,115,120$, 128]. Similar to cytotoxic drugs, Yunzhi and its components could also act on the (a) expression of cell cycle arrest and apoptosis related genes and proteins, including Fas and Fasl [113]; Bax, Bcl-2, and BH3 interactingdomain death agonist (Bid) [128-130]; nuclear factor- $\mathrm{kB}$ (NF-kB) [115, 117, 120]; cellular inhibitor of apoptosis protein 1 (cIAP-1) [120] and caspase-3 [113, 120] and (b) targets related to angiogenesis and cell invasion, including matrix metallopeptidase 9 (MMP-9) [115], leading to synergistic effect when they are used together. 
Yunzhi could also enhance the cytotoxicity of anticancer drugs via other mechanisms, such as direct increase in the activity of cytotoxic and tumor-infiltrating lymphocytes, decrease in the activity of suppressor T cells [38, 70], and decrease and increase in superoxide dismutase (SOD) and lipid peroxide levels, respectively, in cancer cells [131]. In addition, PSK was shown to enhance the antitumor effect of 5-FU and Tegafur by downregulating the expression of dihydropyrimidine dehydrogenase messenger RNA (mRNA) [118], as well as docetaxel via the suppression of survivin expression activated by docetaxel [117].

\section{Interaction on immune system a. Clinical evidence}

In clinical studies, Lingzhi co-administration with cytotoxic drugs generally relieved bone marrow suppression. The combinations alleviated the decrease in white blood cells (WBCs), including lymphocytes and neutrophils, caused by chemotherapy alone (5-FU, capecitabine, cisplatin, doxorubicin, gemcitabine, leucovorin, mitomycin, oxaliplatin, paclitaxel, and vinorelbine). The number of other blood cells, including red blood cells (RBCs), hemoglobin, and platelets was also increased by the combinations compared with chemotherapy alone [19-21, 52-57, $59,77,78,132-134]$. Specifically, some combinations alleviated the decrease in or induced an increase in some $\mathrm{T}$ cells (CD3+, CD4+, CD8+), CD4+/CD8+ ratio and natural killer (NK) cells [19, 20, 52-55, 59, 76-78, 132-134].

Co-administrations of Yunzhi with various cytotoxic drugs (capecitabine, mercaptopurine, oxaliplatin, and Tegafur) were also shown to reduce immunosuppression in clinical studies $[47,48,50,135]$. Studies have shown a reversal of the decrease in WBCs, in particular, improvement of the increase in or alleviation of the decrease in $\mathrm{T}$ cells (CD3+, CD4+, CD8+), increase in the CD4+/ $\mathrm{CD} 8+$ ratio, NK cell activity, and subsequent the production of immunoglobulins and interleukins (IL) [23, 38, 49, $60,62,68,79,80,136-144]$. Inhibition on other blood cells, such as platelets and hemoglobin by cytotoxic drugs were also alleviated by the co-administered Yunzhi [80, 136-140, 144].

\section{b. Preclinical and mechanistic studies}

Animal studies also showed alleviation in the WBCs decrease with the co-administration of Lingzhi and different cytotoxic drugs, particularly in $\mathrm{T}$ cells and NK cells $[65,66,81,83-85,87,89,90,125-127,145-158$, 163]. In addition, phagocytic activity and production of cytokines, including immunoglobulins, interferons (IFN), IL, and TGF, were shown to be restored [64, 81, 85, 88-90, 127, 146, 149-151, 153, 155, 156, 158-162, 165]. Suppression in the number of RBCs, platelets, and in hemoglobin was also found to be alleviated in animal studies [83, 84, 87, 150, 153, 156, 157, 163-165].
The co-administration of Yunzhi with cytotoxic drugs showed similar effects on immune function in animal studies as those observed in clinical studies. Immunosuppression was reduced, including alleviation of the decrease in WBCs, particularly B cell and T cells (CD3+ and $\mathrm{CD} 4+$ ); increase in the CD4+/CD8+ ratio, NK cells and phagocytic activity; and subsequent production of interleukins, immunoglobulins, and antibodies [69, 73, $111-114,129,130,148,166-168]$. Inhibition on other blood cells, including hemoglobin, also was alleviated [69].

A complete understanding of the mechanisms and factors underlying the effects of the interaction of Lingzhi or Yunzhi with cytotoxic drugs on the immune system is still obscure. Multiple mechanisms may be involved, including upregulation of transcription factors such as T-box protein expressed in T cells (T-bet) and GATA-3, which modulate the $\mathrm{T}$ helper cell balance [169]; downregulation of Bax expression to reduce caspase 3 activity and $\mathrm{T}$ cell apoptosis [170]; and reduction of the expression of negative regulators/transcription factors of immune responses, including Forkhead box protein 3 (Foxp3) and programmed death 1 (PD-1) [171].

\section{Alleviation of the other adverse effects of cytotoxic drugs a. Clinical evidence}

The co-administration of Lingzhi with some cytotoxic drugs (5-FU, capecitabine, cisplatin, doxorubicin, gemcitabine, leucovorin, mitomycin, oxaliplatin, and paclitaxel) was shown to reduce common adverse effects, such as reduction of gastrointestinal discomfort (nausea, vomiting, constipation, and diarrhea) and stomatitis $[19,53,56$, $59,77,78]$. Specific adverse effect, such as nephrotoxicity [56] was also shown to be ameliorated.

In clinical studies on Yunzhi, the use of PSK and PSP with cytotoxic drugs (5-FU, capecitabine, mitomycin, oxaliplatin, and UFT) ameliorated the general adverse effects, such as gastrointestinal discomfort (nausea and vomiting, diarrhea, and constipation) [48, 61, 136], mucositis [48], and fatigue [136]. Specific adverse effects of cytotoxic drugs, including peripheral neuropathy [143], mutations [172], and hand-foot syndrome [48], were also reduced.

\section{b. Preclinical and mechanistic evidence}

The Lingzhi and cytotoxic drug combinations were also found to relieve some adverse effects in animal studies; for example, they reduced damage to different organs, including the intestine $[162,173]$, the kidney [64-66, 174-180], the liver [66, 86, 157, 164, 165], and the heart $[157,181,182]$; and their adverse effects, such as nausea and vomiting [147, 183, 184], mutation [185], and neural tube defects [186]. 
Some studies have evaluated the mechanism underlying the protective effects of the mushroom-drug combinations against chemotherapy-induced side effects. For example, the mechanism underlying the reduction of doxorubicin-induced myocardial damage was found to be via the modulation of cardiac enzymes and reduction of the oxidative stress (such as increase in glutathione S-transferase (GST) and glutathione peroxidase (GPx) levels) in myocardial cells by Lingzhi or Ganoderma polysaccharides [181, 182]. Similarly, Lingzhi and its polysaccharides likely increased renocortical antioxidant levels and relieved the oxidative stress, thereby ameliorating cisplatin-induced renal damage. Furthermore, Lingzhi reduced the occurrence of neural tube defects caused by retinoic acid by upregulating the transcription of cyclin-dependent kinase 4 (CDK4) mRNA and the expression of CDK4 and nestin in neural epithelia [186].

For Yunzhi animal studies, cisplatin-induced renal damage was reduced by decreasing blood urea nitrogen (BUN) and serum creatinine (Scr) levels [166]. In both animal and in-vitro studies, PSK reduced the mutagenicity of mitomycin by decreasing the frequency of sister chromatid exchange and micronuclei formation $[187,188]$.

In summary, the aforementioned outcomes suggest that medicinal mushrooms have great potential to ameliorate the adverse effects of chemotherapeutic drugs in clinical settings.

Other effects in pre-clinical studies Several chemotherapy drugs are known to cause oxidative stress which damage tumor cells but concomitantly damage normal cells and produce adverse effects [189]. The co-administration of Lingzhi with cytotoxic drugs, including cisplatin, cyclophosphamide, doxorubicin, and methotrexate increased the total antioxidant capacity and levels of different antioxidant enzymes, including superoxide dismutase (SOD), glutathione, GPx, and catalase, and decreased malondialdehyde levels, thereby reducing the oxidative stress $[64,81,150,157,162,175-182$, 190-192]. In an in-vitro study, the co-administration of Yunzhi with cisplatin prevented the decrease in SOD activity by mimicking it to protect normal healthy cells while selectively promoting the decrease in SOD activity and increase in lipid peroxide levels in cancer cells, both of which synergistically increased tumor inhibition while leaving normal cells unaffected [131]. However, these findings have not yet been substantiated in clinical settings.

\section{Undesirable interaction outcome}

Overall, there is no reported undesirable herb-drug interaction between Lingzhi or Yunzhi and cytotoxic drugs in our included studies. Although interaction between PSP and cyclophosphamide may potentially increase the systemic exposure of cyclophosphamide, it is not known whether it could lead to significant changes in clinical outcomes [193]. Since our findings indicated that Lingzhi/Yunzhi and their components may potentially affect pharmacokinetics of anticancer drug, further clinical pharmacokinetic studies are warranted to investigate the necessity for dose adjustment of anticancer drug in clinical practice.

\section{Quality of clinical studies}

The clinical studies on the concurrent use of Lingzhi or Yunzhi with cytotoxic drugs were rated using the Jadad scale. Overall, most of the clinical studies on the combined use of mushrooms and cytotoxic drugs were not of high quality, scoring mostly $0-3$ points. Most of them did not adopt blinding measures, probably because it is not feasible to blind chemotherapy regimens and complex herbal therapies. In addition, many studies lacked comprehensive description of withdrawal and dropouts. Only half of the randomized studies provided details on their randomization methods. Similar to the findings from others on clinical trials with Chinese medicine [194], the trials involved in the current review were also with poor clinical trial design and insufficient reporting of studies. Although the SPIRIT 2013 and CONSORT 2010 guideline have been published with intent to improve the design and reporting of randomized controlled trials, they may not be completely applied to the trials of Chinese medicine formulas. Thus, a CONSORT 2010 extension and SPIRIT-TCM extension have been established in 2017 and 2018 respectively to meet the unique characteristics of Chinese medicine $[195,196]$, which could serve as the guidance for future clinical studies involved Chinese medicines.

\section{Conclusion and implication for future study}

The combination of Lingzhi and Yunzhi with cytotoxic anti-cancer drugs showed great potential in offering beneficial effects in clinical settings with no undesirable interactions reported so far. The survival benefits can be increased, especially for Lingzhi and the quality of life of cancer patients can be enhanced especially for Yunzhi. Both Lingzhi and Yunzhi showed synergistic effect on tumor inhibition with chemotherapy, reducing immunosuppression and alleviating general and specific chemotherapy related side effects. 
Despite a relatively large number of clinical studies conducted, the quality of clinical studies included in this review remained not high, especially with lack of blinding and description of all withdrawals and dropouts. Trials based on guidance from CONSORT 2010 extension and SPIRIT-TCM extension are highly recommended in the future to ensure the higher quality of clinical trial on Chinese medicines. Pharmacokinetic effects of Lingzhi or Yunzhi on cytotoxic drugs were inconclusive. There was currently significantly lack of studies on pharmacokinetic herb-drug interactions as revealed above. Considering the narrow therapeutic index of many cytotoxic drugs, more clinical pharmacokinetic studies are warranted for their safe and effective use.

In recent years, there are revolutionary advancements in the oncology world that sees many new breakthrough treatments, including targeted therapies, immunotherapy as well as gene therapy. Future studies should identify potential synergistic and harmful interaction between Chinese Medicine and these advanced cancer therapies. With increasing number of studies on combined usage of Chinese and western medicine, future studies can harness modern techniques such as bioinformatics and data mining to identify patterns of herb-herb and drug-herb combinations, especially those show the strongest evidence for tumor inhibition. Moreover, considering the large population utilizing Chinese Medicine in Asian countries and increasing prevalence in Europe and US, future pharmacoepidemiology studies can be conducted to observe the clinical impact of integrative medicine among cancer patients in a real word setting, in particular long-term and delayed effect that cannot be revealed in ordinary clinical trial settings.

\section{Supplementary information}

Supplementary information accompanies this paper at https://doi. org/10.1186/s13020-020-00356-4.

Additional file 1. Table S1. Keywords for cytotoxic drugs in the current database search. Table S2. Characteristics of included studies. Table S3. Detailed information of the included clinical studies. Table S4. Detailed information of the included pre-clinical studies. Figure S1. Distribution of pre-clinical and clinical studies for combination use of cytotoxic drugs with Lingzhi and Yunzhi.

\footnotetext{
Abbreviations

5-FU: 5-Fluorouracil; ABCB1: ATP binding cassette subfamily B member 1; Akt: Protein kinase B; ALP: Alkaline phosphatase; ALT: Alanine transaminase; AST: Aspartate aminotransferase; Bax: BCl-2-associated X; BCl: B-cell lymphoma; bFGF: Basic fibroblast growth factor; Bid: $\mathrm{BH} 3$ interacting-domain death agonist; BMS: Bone marrow suppression; BUN: Blood urea nitrogen; CDK4: Cyclindependent kinase 4; CEA: Carcinoembryonic antigen; CIAP-1: Cellular Inhibitor of Apoptosis Protein 1; CK: Creatine kinase; DC: Dendritic cells; Fasl: Fas ligand; Foxp3: Forkhead box P3; GPx: Glutathione peroxidase; GST: Glutathione S-transferase; HER2: Human epidermal growth factor receptor 2; IFN: Interferon; IL: Interleukin; JAK-STAT3: Janus kinase/signal transducer and activator
}

of transcription 3; LBT: Lymphocyte blastogenic transformation; LDH: Lactate dehydrogenase; MDA: Malondialdehyde; miR-21: microRNA 21; MMP-9: Matrix metallopeptidase 9; mRNA: Messenger RNA; NAG: N-acetyl-beta-D-glucosaminidase; NF-kB: Nuclear factor-kB; NK: Natural killer; PD-1: Programmed death 1; PI3K: Phosphoinositide 3-kinase; PSK: Polysaccharide K; PSP: Polysaccharide peptide; p53: Tumor protein p53; RBC: Red blood cells; Scr: Serum creatinine; Smad4: Mothers against decapentaplegic homolog 4; sMICA: Soluble major histocompatibility complex class I-related chain A; SOD: Superoxide dismutase; T-bet: T-box protein expressed in T cells; TGF: Transforming growth factor; TMSG-1:Tumor metastasis suppressor gene 1; UFT:Tegafur/uracil;VEGF: Vascular endothelial growth factor; WBC: White blood cells.

\section{Acknowledgements}

Not applicable.

\section{Authors' contributions}

Conception or design of the work: All authors. Data acquisition from literature search: CSL and LPC. Analysis and interpretation of data: All. Drafting the work: CSL. Revising it critically for important intellectual content: All. Final approval of the version to be published: All. Agreement to be accountable for all aspects of the work in ensuring that questions related to the accuracy or integrity of any part of the work are appropriately investigated and resolved: All. All authors read and approved the final manuscript.

\section{Funding}

Not applicable.

Availability of data and materials

Not applicable.

Ethics approval and consent to participate

Not applicable.

\section{Consent for publication}

Not applicable.

\section{Competing interests}

The authors declare that they have no competing interests.

\section{Author details}

${ }^{1}$ School of Pharmacy, Faculty of Medicine, The Chinese University of Hong Kong, Shatin, N.T., Hong Kong, People's Republic of China. ${ }^{2}$ School of Chinese Medicine, Hong Kong Baptist University, Kowloon City, Hong Kong, People's Republic of China.

Received: 20 May 2020 Accepted: 20 July 2020

Published online: 25 July 2020

References

1. Carmady B, Smith CA. Use of Chinese medicine by cancer patients: a review of surveys. Chin Med. 2011;6:22.

2. Lam Y, Cheng C, Peng H, Law C, Huang X, Bian Z. Cancer patients' attitudes towards Chinese medicine: a Hong Kong survey. Chin Med. 2009;4:25.

3. Yeh Y, Chou Y, Huang N, Pu C, Chou P. The trends of utilization in traditional Chinese medicine in Taiwan from 2000 to 2010: a populationbased study. Medicine (Baltimore). 2016:95(27):e4115.

4. Ramos-Esquivel A, Víquez-Jaikel Á, Fernández C. Potential drug-drug and herb-drug interactions in patients with cancer: a prospective study of medication surveillance. J Oncol Pract. 2017;13(7):e613-22.

5. McCune JS, Hatfield AJ, Blackburn AAR, Leith PO, Livingston RB, Ellis GK. Potential of chemotherapy-herb interactions in adult cancer patients. Support Care Cancer. 2004;12(6):454-62

6. Patel S, Goyal A. Recent developments in mushrooms as anti-cancer therapeutics: a review. 3 Biotech. 2012;2(1):1-15.

7. National Pharmacopoeia Committee. Pharmacopoeia of the People's Republic of China Part 1. 2015.

8. Zhong L, Yan P, Lam WC, et al. Coriolus versicolor and Ganoderma lucidum related natural products as an adjunct therapy for cancers: a 
systematic review and meta-analysis of randomized controlled trials. Front Pharmacol. 2019;10:703.

9. Jin X, Ruiz Beguerie J, Sze D, Chan GCF. (Reishi mushroom) for cancer treatment. Cochrane Database Syst Rev. 2016;4:CD007731.

10. Wong LY, Cheng KF, Leung PC. Efficacy of Yun Zhi (Coriolus versicolor) on survival in cancer patients: systematic review and meta-analysis. Recent Pat Inflamm Allergy Drug Discov. 2012;6(1):78-87.

11. Jadad AR, Moore RA, Carroll D, et al. Assessing the quality of reports of randomized clinical trials: is blinding necessary? Control Clin Trials. 1996;17(1):1-12.

12. Anai H, Sakaguchi Y, Emi Y, Kohnoe S, Maehara Y, Sugimachi K. A protein-bound polysaccharide immunomodulator, PSK, does not suppress the conversion from 1-(2-tetrahydrofuryl)-5-fluorouracil to 5-fluorouracil in patients with gastric cancer. Anticancer Drugs. 1991;2(3):275-8.

13. Maehara Y, Tamada R, Miyahara M, Notsuka T, Kano T, Kumashiro R, Inokuchi K. Influence of PSK on the metabolism of FT-207. Gan To Kagaku Ryoho. 1984;11(9):1843-7.

14. Liu DL, Li YJ, Yang DH, Wang CR, Xu J, Yao N, Zhang XQ, Chen ZS, Ye WC, Zhang DM. Ganoderma lucidum derived ganoderenic acid B reverses ABCB1-mediated multidrug resistance in HepG2/ADM cells. Int J Oncol. 2015;46(5):2029-38

15. Li W, Zhang B, Wei R, Liu J, Lin Z. Reversal effect of Ganoderma lucidum polysaccharide on multidrug resistance in K562/ADM cell line. Acta Pharmacol Sin. 2008:29(5):620-7.

16. Shukla S, Ohnuma S, Ambudkar SV. Improving cancer chemotherapy with modulators of $A B C$ drug transporters. Curr Drug Targets. 2011:12(5):621-30.

17. Fujita H, Ogawa K, Ikuzawa M, Muto S, Matsuki M, Nakajima S, Shimamura M, Togawa M, Yoshikumi C, Kawai Y. Effect of PSK, a protein-bound polysaccharide from Coriolus versicolor, on drug-metabolizing enzymes in sarcoma-180 bearing and normal mice. Int J Immunopharmacol. 1988;10(4):445-50.

18. Chan S, Yeung JHK. Effects of polysaccharide peptide (PSP) from Coriolus versicolor on the pharmacokinetics of cyclophosphamide in the rat and cytotoxicity in HepG2 cells. Food Chem Toxicol. 2006;44(5):689-94.

19. Zhou DQ. 60 examples of cancer treatment with laojunxian oral liquids and chemotherapy. Forum Trad Chin Med. 1997;12(2):32.

20. Zhang XY, Chang SC. Observation of curative effect of shenlongjinling pills in treating lung cancer. Chin Trad Patent Med. 2002;24(11):902-4.

21. Hu ZP, Gan N. A randomized parallel controlled study of TCM of bailonglingshatang combinated chemotherapy in the treatment of advanced non-small cell lung cancer. J Pract Trad Chin Med. 2013:18:26.

22. Yamashita K, Ougolkov AV, Nakazato H, Ito K, Ohashi Y, Kitakata H, Yasumoto K, Omote K, Mai M, Takahashi Y, Minamoto T. Adjuvant immunochemotherapy with protein-bound polysaccharide $\mathrm{K}$ for colon cancer in relation to oncogenic beta-catenin activation. Dis Colon Rectum. 2007;50(8):1169-81.

23. Hsu JT, Hsu CS, Le PH, Chen TC, Chou WC, Lin CY, Yeh TS. Immunochemotherapy benefits in gastric cancer patients stratified by programmed death-1 ligand-1. J Surg Res. 2016;211:30-8.

24. Mitomi T, Tsuchiya S, lijima N, Aso K, Suzuki K, Nishiyama K, Amano T, Takahashi T, Murayama N, Oko H, Oya K, Noto T, Ogawa N. Randomized, controlled study on adjuvant immunochemotherapy with PSK in curatively resected colorectal cancer. The cooperative study group of surgical adjuvant immunochemotherapy for cancer of colon and rectum (kanagawa). Dis Colon Rectum. 1992;35(2):123-30.

25. Yutaka T, Masayoshi M, Hiroaki N. Preoperative CEA and PPD values as prognostic factors for immunochemotherapy using PSK and 5-FU. Anticancer Res. 2005;25(2B):1377.

26. Nakazato H, Koike A, Saji S, Ogawa N, Sakamoto J. Efficacy of immunochemotherapy as adjuvant treatment after curative resection of gastric cancer. Lancet. 1994;343(8906):1122-6.

27. Yamagiwa M, Miyoshi Y, Sakakura Y, Yamada S, Sakata F, Nishioka H. A clinical study of PSK in head and neck malignancy. Practica Oto-RhinoLaryngologica. 1981;74(4):499-509.

28. Sakamoto J. Evaluation of adjuvant immunochemotherapy with PSK for gastric cancer in a randomized controlled clinical trial. Biother Tokyo. 1996;10:9-17.

29. Ogoshi K, Isono K. HLA-B54 is a candidate of response to fluoropyrimidine plus PSK therapy in gastric cancer. Ann Cancer Res Ther. 2009:17:40-4.
30. Mukai M, Tajima T, Nakasaki H, Sato S, Ogoshi K, Makuuchi H. Efficacy of postoperative adjuvant oral immunochemotherapy in patients with dukes' B colorectal cancer. Ann Cancer Res Ther. 2003:11:215-29.

31. Kuroda Y, Horikawa N, Tsuji M, Yokoyama Y, Kimura H, Maeda K, Yabushita K, Konishi K. Usefulness of polysaccharide K (PSK) as postoperative adjuvant immunotherapy in patients with stage IV gastric cancer. Int J Clin Oncol. 1998;3(5):311-6.

32. Xu FJ, Han SL, Xu YC. Effect of postoperative adjuvant immunochemotherapy for stage III gastric cancer. Chin I Clin Oncol Rehabil. 2003;10(1):47-50

33. Kano T, Kumashiro R, Masuda H, Tamada R, Inokuchi K. Late results of postoperative long-term cancer chemotherapy for the gastric cancer patients subjected to curative resection. Jpn J Surg. 1983;13(2):112-6.

34. Kano T, Kumashiro R, Tamada R, Kodama Y, Inokuchi K. Late results of postoperative long term cancer chemotherapy for advanced carcinoma of the stomach. Jpn J Surg. 1981;11(4):291-6.

35. Kodama Y, Kano T, Tamada R, Kumashiro R, Okamura T, Inokuchi K. Combined effect of prophylactic lymphadenectomy and long term combination chemotherapy for curatively resected carcinoma of the stomach. Jpn J Surg. 1982:12(4):244-8.

36. Kano T, Tamada R, Abe Y, Hiramoto Y, Notsuka T, Shiraishi M, Inoue F, Kumashiro R, Kodama Y, Inokuchi K. Postoperative long-term cancer chemotherapy (PLCC) extends life-span of non-curatively resected patients with stage IV gastric cancer. Jpn J Surg. 1982;12(3):203-7.

37. Kaibara N, Soejima K, Nakamura T, Inokuchi K. Postoperative long term chemotherapy for advanced gastric cancer. Jpn J Surg. 1976;6(2):54-9.

38. Ohwada S, Ogawa T, Makita F, Tanahashi Y, Ohya T, Tomizawa N, Satoh Y, Kobayashi I, Izumi M, Takeyoshi I, Hamada K, Minaguchi S, Togo Y, Toshihiko T, Koyama T, Kamio M. Beneficial effects of protein-bound polysaccharide K plus tegafur/uracil in patients with stage II or III colorectal cancer: analysis of immunological parameters. Oncol Rep. 2006;15(4):861-8.

39. Akagi J, Baba H. PSK may suppress CD57(+) T cells to improve survival of advanced gastric cancer patients. Int J Clin Oncol. 2010;15(2):145-52.

40. Niimoto M, Hattori T, Tamada R, Sugimachi K, Inokuchi K, Ogawa N. Postoperative adjuvant immunochemotherapy with mitomycin C, futraful and PSK for gastric cancer. An analysis of data on 579 patients followed for five years. Jpn J Surg. 1988;18(6):681-6.

41. Namikawa T, Fukudome I, Ogawa M, Munekage E, Munekage M, Shiga M, Maeda H, Kitagawa H, Kobayashi M, Hanazaki K. Clinical efficacy of protein-bound polysaccharide $\mathrm{K}$ in patients with gastric cancer undergoing chemotherapy with an oral fluoropyrimidine (S-1). Eur J Surg Oncol. 2015;41(6):795-800.

42. Ohwada S, Ikeya T, Yokomori T, Kusaba T, Roppongi T, Takahashi T, Nakamura S, Kakinuma S, Iwazaki S, Ishikawa H, Kawate S, Nakajima T, Morishita Y. Adjuvant immunochemotherapy with oral tegafur/uracil plus PSK in patients with stage II or III colorectal cancer: a randomised controlled study. Br J Cancer. 2004;90(5):1003-10.

43. Ogoshi K, Satou H, Isono K, Mitomi T, Endoh M, Sugita M. Possible predictive markers of immunotherapy in esophageal cancer: retrospective analysis of a randomized study. The cooperative study group for esophageal cancer in Japan. Cancer Invest. 1995;13(4):363-9.

44. Sugimachi K, Maehara Y, Ogawa M, Kakegawa T, Tomita M. Dose intensity of uracil and tegafur in postoperative chemotherapy for patients with poorly differentiated gastric cancer. Cancer Chemother Pharmacol. 1997:40(3):233-8.

45. Yoshitani S, Takashima S. Efficacy of postoperative UFT (tegafur/uracil) plus PSK therapies in elderly patients with resected colorectal cancer. Cancer Biother Radiopharm. 2009;24(1):35-40.

46. Sakai T, Yamashita Y, Maekawa T, Mikami K, Hoshino S, Shirakusa T. Immunochemotherapy with PSK and fluoropyrimidines improves longterm prognosis for curatively resected colorectal cancer. Cancer Biother Radiopharm. 2008;23(4):461-7.

47. Hattori T, Niimoto M, Koh T, Nakano A, Oride M, Takiyama W, Nishimawari K. Post-operative long-term adjuvant immunochemotherapy with mitomycin-C, PSK and FT-207 in gastric cancer patients. Jpn J Surg. 1979;9(2):110-7.

48. Xu S, Song YH, Li H, Cai HB. Study of efficacy of Yunzhi polysaccharides with XELOX in treatment of late stage colorectal cancer. Acta Universitatis Medicinalis Nanjing. 2008;28(12):1616-8. 
49. Lu JR, Liu WS, Xu K, Wu WY, Liu YL, Zhu DY. A clinical observation of Xiaoji decoction for intermediate and late stages of lung cancer. J Guangzhou Univ Trad Chin Med. 2001;18(3):195-201.

50. Nagao T, Komatsuda M, Yamauchi K, Nozaki H, Watanabe K, Arimori S. Chemoimmunotherapy with Krestin in acute leukemia. Tokai J Exp Clin Med. 1981;6(2):141-6.

51. Ishibashi K, Ishiguro T, Kuwabara K, Ohsawa T, Okada N, Miyazaki T, Yokoyama M, Matsuki M, Ishida H. Administration of polysaccharide K (PSK) for stage III colorectal cancer in clinical practice. Gan To Kagaku Ryoho. 2008;35(12):2283-5.

52. Jing JJ, Zhu XQ, Li BY, Jie Y. Clinical observation comparison of Bailong capsules and oral liquids with chemotherapy in gastrointestinal cancer. Shanxi Med J. 2007;36(13):631-3.

53. Wang YH, Qu ZH, Qin Y. Clinical observation of cracked Lingzhi spore powder with oxaliplatin and capecitabine in treatment of late stage colorectal cancer. China Pract Med. 2014;21:108-9.

54. Li YQ, Zhang HM. 56 clinical case studies of Laojunxian Lingzhi oral liquid with chemotherapy in treatment of intermediate and late stage of non small cell lung cancer. Chin J Cancer Biother. 1997;3:179.

55. Chen WJ, Hua HJ, Lu LS, Ouyang GF. Effect on immune function of Yangzhengxiaoji capsule in late stage non small cell lung cancer. Fujian J TCM. 2015;1:16-7.

56. Zhang $X$, Ye LH, Peng HY, Zhang YH. Clinical investigation of treating advanced non small cell lung cancer (NSCLC) by tonifying deficiency and resolving toxin prescription combined with chemotherapy. J Liaoning Univ TCM. 2010;12(9):23-4

57. Xu ZY, Jin CJ, Zhou CC, Wang ZQ, Zhou WD, Deng HB, Zhang M, Su W, Cai XY. Treatment of advanced non-small-cell lung cancer with Chinese herbal medicine by stages combined with chemotherapy. J Cancer Res Clin Oncol. 2011;137(7):1117-22.

58. Xie SY. A randomized parallel controlled study on the treatment of elderly patients with lung cancer chemotherapy with modified TP chemotherapy. J Pract Trad Chin Intern Med. 2016;19(2):33-5.

59. Lu M. Clinical research of combination of Chinese and western medicine treatment of middle and advanced gastric cancer. China J Chin Med. 2013:28(8):1104-5.

60. Yan W, Zhu YP, Sun TW. The effect of PSP on immune function and living quality in patients receiving chemotherapy for gynecological malignancies. J Shanghai Teachers Univ (Natural Sciences). 2000;29(2):75-8.

61. Miyake Y, Nishimura J, Kato T, Ikeda M, Tsujie M, Hata T, Takemasa I, Mizushima T, Yamamoto H, Sekimoto M, Nezu R, Doki Y, Mori M. Phase II trial comparing UFT + PSK to UFT + LV in stage IIB, III colorectal cancer (MCSGO-CCTG). Surg Today. 2018;48(1):66-72.

62. Han LC, Zhang LJ, Song L, Chen WQ, Xiu YD. Clinical study on Yunzhi Tangtai capsules combined with TC regimen in treatment of esophageal cancer. Drugs Clin. 2019;34(1):3076-81.

63. Furusawa E, Chou SC, Furusawa S, Hirazumi A, Dang Y. Antitumour activity of Ganoderma lucidum, an edible mushroom, on intraperitoneally implanted Lewis lung carcinoma in synergenic mice. Phytother Res. 1992;6(6):300-4.

64. Ouyang MZ, Lin LZ, Lv WJ, Zuo Q, Lv Z, Guan JS, Wang ST, Sun LL, Chen $H R$, Xiao ZW. Effects of the polysaccharides extracted from Ganoderma lucidum on chemotherapy-related fatigue in mice. Int J Biol Macromol. 2016;91:905-10

65. Zhao SL, Nie YZ, Liang GN, Chen LL, Hou YY. Ganoderma lucidum polysaccharides combined with low-dose cisplatin inhibits tumor growth and enhances the immune function of tumor-bearing mice. Int J Trad Chin Med. 2012:34(12):1084-7.

66. Zhu J, Xu J, Jiang LL, Huang JQ, Yan JY, Chen YW, Yang Q. Improved antitumor activity of cisplatin combined with Ganoderma lucidum polysaccharides in U14 cervical carcinoma-bearing mice. Kaohsiung J Med Sci. 2019:35(4):222-9.

67. Nie K. Effect of Sanghuang Yunzhi capsule on survival of tumor-bearing mice. Pharmacol Clin Chin Mater Med. 2009:25(3):61-2.

68. Katoh R. Effects on host of VP therapy with PSK on lung cancer. Biotherapy Tokyo. 1998;12:667-9.

69. Shen XH, Chen CX, Gao YT. The action-enhancing and toxicityreducing effects of a new Coriolus versicolor polysaccharide peptide with cyclophosphamide on S180 sarcoma xenografted mice. Tumor. 2008:28(7):572-6.
70. Ueno Y, Kohgo Y, Sakamaki S, Itoh Y, Takahashi M, Hirayama Y, Niitsu Y. Immunochemotherapy in B-16-melanoma-cell-transplanted mice with combinations of interleukin-2, cyclophosphamide, and PSK. Oncology. 1994;51(3):296-302.

71. Mizushima Y, Yuhki N, Hosokawa M, Kobayashi H. Diminution of cyclophosphamide-induced suppression of antitumor immunity by an immunomodulator PS-K and combined therapeutic effects of PS-K and cyclophosphamide on transplanted tumor in rats. Cancer Res. 1982:42(12):5176-80.

72. Iwaguchi T, Shimizu M, Hayashi H. Analysis of electrophoretic mobility histograms of mouse splenocytes and thymocytes during tumor growth and after combined chemotherapy and immunotherapy. J Biochem Biophys Methods. 1989;18(2):157-66.

73. Fujii T, Sugita N, Kobayashi Y, Saito K, lijima H, Matsunaga K, Ando T, Oguchi Y, Morita I, Yoshikumi C, Nomoto K. Treatment with Krestin combined with mitomycin C, and effect on immune response. Oncology. 1989;46(1):49-53.

74. Oh-hashi F, Kataoka T, Tsukagoshi S. Effect of combined use of anticancer drugs with a polysaccharide preparation, Krestin, on mouse leukemia P388. GANN Jpn J Cancer Res. 1978;69(2):255-7.

75. Choi JH, Ahn MJ, Rhim HC, Kim JW, Lee GH, Lee YY, Kim IS. Comparison of WHO and RECIST criteria for response in metastatic colorectal carcinoma. Cancer Res Treat. 2005;37(5):290-3.

76. Yan FF. Effect of Ganoderma capsule on expressions of CD105 protein and miR-21 in cervical cancer tumor tissue associated with HPV infection. Chin J Biochem Pharm. 2017;37(03):131-4.

77. Zhao FY, Wu Q, Li YM, Wang R. Efficacy and effect on immune function of Fufang Lingzhi Baozi capsule with chemotherapy in non small cell lung cancer. Chin J Gerontol. 2015;10:2721-2.

78. Wang J, Chen ZQ, Li Y, Wang XS, Fei CL, Wang SJ. Clinical efficacy and effect on immune function of Fufang Lingzhi Baozi capsule with chemotherapy in non small cell lung cancer. Mod J Integr Trad Chin Western Med. 2016:25(24):2673-5.

79. Wang CJ, Cai SY, Liu JB, Cai K. Observational study of clinical efficacy of PSP capsules with chemotherapy in intermediate and late stages of lung cancer. Anthol Med. 2000;19(6):871-2.

80. Wang B, Jia YD, Jia YJ, Zhao C, Chen J, Sun YY, Fang WY. Clinical observation of Yunzhijun capsules on increasing efficacy and reducing toxicity in late stage primary hepatic carcinoma. World Chin Med. 2009;4:202-3.

81. Li W, Nie S, Chen Y, Wang Y, Li C, Xie M. Enhancement of cyclophosphamide-induced antitumor effect by a novel polysaccharide from Ganoderma atrum in sarcoma 180-bearing mice. J Agric Food Chem. 2011;59(8):3707-16

82. Sukegawa Y, Kawamura J, Okuno K. Survival benefit by combined administration of cyclophosphamide, Lentinula edodes mycelia extract(LEM), and Ganoderma lucidum mycelia extract (MAK) in S1018B10 tumor-bearing mice. Gan To Kagaku Ryoho. 2017:44(10):896-9.

83. Chen $\mathrm{CH}$, Fang $\mathrm{TH}, \mathrm{Xu} \mathrm{L}$, Zhou LL, Jia M. Toxin-attenuating and efficacy-enhancing effect of compound Lingzhi Baozi oil on S180 tumor-bearing mice after chemotherapy. J Nanjing Univ Trad Chin Med (Natural Sciences). 2008;24(2):127-9.

84. Liu YF, Tang QJ, Zhang JS, Yang Y, Zhou S, Wu D, Jia W, Feng N. Monosaccharide composition analysis of two polysaccharide fractions from Ganoderma lucidum and their effects on inhibiting tumor growth in mice by 5-fluracil. Food Sci. 2011;32(11):288-91.

85. Zhang GQ, Zhu XX, Fu R, Zhang D, Zhang XF. Efficiency-enhancing and toxicity-reducing effects of Ganoderma spore oil on cyclophosphamide treatment of mouse HepS. Chin Arch Trad Chin Med. 2014;32(11):2690-3.

86. Ma ZH, Wu SH, Shi H, Liu H, Wang ZY, Shi YE. Synergy and attenuation of Fuxi Lingzhi on cyclophosphamide. J Hebei Trad Chin Med Pharmacol. 2011;26(1):34-5.

87. Zhang JJ, Liao XY, Weng XC. Efficacy of compound of Ganoderma lucidum and Astragalus extracts on tumor-bearing mice treated by cyclophosphamide. J Shanghai Univ (Natural Science). 2012;18(4):425-9.

88. Tang XM, Wu ZX. In-vitro and in vivo anti-tumor effects of Ganoderma compound. J Trad Chin Med. 2013;54(15):1323-6.

89. Li WJ, Chen Y, Nie SP, Xie MY, He M, Zhang SS, Zhu KX. Ganoderma atrum polysaccharide induces anti-tumor activity via the mitochondrial 
apoptotic pathway related to activation of host immune response. $J$ Cell Biochem. 2011;112(3):860-71.

90. Nonaka Y, Ishibashi H, Nakai M, Shibata H, Kiso Y, Abe S. Effects of the antlered form of Ganoderma lucidum on tumor growth and metastasis in cyclophosphamide-treated mice. Biosci Biotechnol Biochem. 2008;72(6):1399-408.

91. Xie M, Tan YL, Ma MB, Zhou Y, Chen XL. Effect of chemotherapy combined with traditional Chinese medicine on the expression of TMSG-1 in transplantation tumor of human breast cancer in nude mice. J Xiangnan Univ (Medical Sciences). 2013;15(4):1-5.

92. Wu XD, Zhang NB, He RK. Study on inhibition effect of vigor on tumor growth in ehrlich ascites carcinoma (EAC) tumor bearing mice. Chin Med Mod Distance Educ China. 2014;10:158-60.

93. Chen XJ, Shi HL, Feng CP. The study of anti-tumor effect by the combination of SGLK and cyclophosphamide. J Mod Oncol. 2005;12(10):158-60

94. Sun Y, Chen XJ, Wu Q, Gong H. The synergetic anti-tumor effect of the combination of extract from five types of Ganoderma lucidum with cyclophosphamide. J Mod Oncol. 2007;15(5):619-21.

95. Yang C, Ban L, Wang L, Ju YH, Shen LY, Zheng YX, Zhao SF. Expression and significance of let-7 during the nude mouse ovarian carcinoma treated by Ganoderma lucidum spore process. J Med Pest Control. 2015;1:52-3.

96. Zhang ZQ, Xia L, Xiong XW, Li W, Li P, Xu JH. Enhancement of paclitaxe induced apoptosis in HER2 + breast cancer cells by the triterpene component of Ganoderma lucidum. J Fujian Med Univ. 2016;2016-01:1-5.

97. Su J, Li D, Chen Q, Li M, Su L, Luo T, Liang D, Lai G, Shuai O, Jiao C, Wu $\mathrm{Q}$, Xie Y, Zhou X. Anti-breast cancer enhancement of a polysaccharide from spore of Ganoderma lucidum with paclitaxel: suppression on tumor metabolism with gut microbiota reshaping. Front Microbiol. 2018:9:3099.

98. Opattova A, Horak J, Vodenkova S, Kostovcikova K, Cumova A, Macinga P, Galanova N, Rejhova A, Vodickova L, Kozics K, Turnovcova K, Hucl T, Sliva D, Vodicka P. Ganoderma lucidum induces oxidative DNA damage and enhances the effect of 5-Fluorouracil in colorectal cancer in vitro and in-vivo. Mutat Res Genet Toxicol Environ Mutagenesis. 2019;845:403065.

99. Liang ZEN, Yi YJ, Guo YT, Wang RC, Xiong XY. Effect of combined Ganoderma lucidum polysaccharides (GLP) and fluorouracil on proliferation and apoptosis in human colon carcinoma HCT-116 cells. Food Sci. 2012;33(19):310-4.

100. Xu J, Wu L, Xu QF. Research about the apoptosis of liver cancer HepG2 cells induced by Ganoderma lucidum polysaccharides. China Mod Med. 2009;16(23):7-9

101. Liang ZEN, Yi YJ, Guo YT, Wang RC, Xiong XY. Effects of combination of Ganoderma lucidum polysaccharides and 5-fluorouracil on proliferation and apoptosis in LoVo cells. Chin Trad Patent Med. 2012;34(11):2068-72.

102. Jiang D, Wang L, Zhao T, Zhang Z, Zhang R, Jin J, Cai Y, Wang F. Restoration of the tumor-suppressor function to mutant p53 by Ganoderma lucidum polysaccharides in colorectal cancer cells. Oncol Rep. 2017:37(1):594-600

103. Chen JS, Ren WS. Increase in efficacy of radiation and chemotherapy by Shuanglinggubensan. Zhejiang J Trad Chin Med. 2007:42(4):241

104. Guo PR, Sheng YW, Liu B, Wang C, Liu YD, Fu DW. Influence of Ganoderma lucidum polysaccharide on the inhibitory effects of cisplatin on the tumor growth and angiogenesis in bladder cancer (T24) cells -bearing nude mice. Med J Chin People's Liberat Army. 2014;39(06):470-4.

105. Zhang $L J$, Zhang $L$. The study of Ganoderma lucidum polysaccharide combined cisplatin on A549 lung cancer cell proliferation inhibition. Mod Prev Med. 2016;9:34

106. Zhao S, Ye G, Fu G, Cheng J, Yang BB, Peng C. Ganoderma lucidum exerts anti-tumor effects on ovarian cancer cells and enhances their sensitivity to cisplatin. Int J Oncol. 2011;38(5):1319-27.

107. Huang CY, Chen JYF, Wu JE, Pu YS, Liu GY, Pan MH, Huang YT, Huang AM, Hwang CC, Chung SJ, Hour TC. Ling-zhi polysaccharides potentiate cytotoxic effects of anticancer drugs against drug-resistant urothelial carcinoma cells. J Agric Food Chem. 2010;58(15):8798-805.

108. Kuo HP, Hsu SC, Ou CC, Li JW, Tseng HH, Chuang TC, Liu JY, Chen SJ, Su MH, Cheng YC, Chou WY. Ganoderma tsugae extract inhibits growth of HER2-overexpressing cancer cells via modulation of HER2/PI3K/Akt signaling pathway. Evid Based Complement Altern Med. 2013. https:// doi.org/10.1155/2013/219472.

109. Qu HG, Gao L, He D, Liu C, Yan W, Gao H, Wang L. Reversal of cisplatininduced drug resistance of ovarian cancer cells by Ganoderma lucidum polysaccharides. Chin J Gerontol. 2011:31(5):831-3.

110. Feng P, Liu C, Yuan YS. Inhibition of Lingzhi spore oil on high K+ channel HERG expression tumor cells and synergistic effect with chemotherapeutic drugs. In: Proceedings of the 9th Chinese National Medicinal Mushroom Conference. 2009 Oct 23-27; Fujian, China. 2009;p. 79-84.

111. Tsuru S, Shinomiya N, Katsura Y, Gotoh M, Noritake M, Nomoto K. Effects of combined therapies with protein-bound polysaccharide (PSK, Krestin) and fluorinated pyrimidine derivatives on experimental liver metastases and on the immunologic capacities of the hosts. Oncology. 1991;48(6):498-504.

112. Deng WL, Ye SJ, Wang WL, Liu JY, Xu JH. Studies on the effects of intracellular polysaccharides of Polystictus versicolor (L.) FR. (IPPV) on the specific immunological functions and on the combined immunopharmacological effects of IPPV and immunosuppressants. Kang Sheng Su. 1985;10(1):47-52.

113. Guo DM, Tian F, Chen LW, Feng J, He L, Wang L. Study on Fas pathway and immune escape and apoptosis protein caspase-3 by CVPS on the human pulmonary adenocarcinoma A549 xenografts in nude mice. In: Chinese Medicine in Oncology Prevention Annual Conference 2012 Sep 14-16; Shanxi, China. 2012. p. 540-6.

114. Wenner CA, Martzen MR, Lu H, Verneris MR, Wang H, Slaton JW. Polysaccharide-K augments docetaxel-induced tumor suppression and antitumor immune response in an immunocompetent murine model of human prostate cancer. Int J Oncol. 2012;40(4):905-13.

115. Yamasaki A, Shoda M, lijima H, Nagai S, Wada J, Suzuki H, Chikazawa N, Tasaka T, Kameda C, Tanaka H, Ikebe M, Jo E, Sato N, Nakamura M, Sekine F, Morisaki T, Katano M. A protein-bound polysaccharide, PSK, enhances tumor suppression induced by docetaxel in a gastric cancer xenograft model. Anticancer Res. 2009;29(3):843-50.

116. Garrido C, Romero I, Berruguilla E, Cancela B, Algarra I, Collado A, GarcíaLora A, Garrido F. Immunotherapy eradicates metastases with reversible defects in MHC class I expression. Cancer Immunol Immunother. 2011;60(9):1257-68.

117. Kinoshita J, Fushida S, Harada S, Makino I, Nakamura K, Oyama K, Fujita H, Ninomiya I, Fujimura T, Kayahara M, Ohta T. PSK enhances the efficacy of docetaxel in human gastric cancer cells through inhibition of nuclear factor-kappaB activation and survivin expression. Int J Oncol. 2010:36(3):593-600

118. Mekata E, Murata S, Sonoda H, Shimizu T, Umeda T, Shiomi H, Naka S, Yamamoto H, Abe H, Edamatsu T, Fujieda A, Fujioka M, Wada T, Tani T. Protein-bound polysaccharide-K augments the anticancer effect of fluoropyrimidine derivatives possibly by lowering dihydropyrimidine dehydrogenase expression in gastrointestinal cancers. Oncol Rep. 2013;30(6):2845-51

119. Umehara S, Fujiwara H, Suchi K, Okamura S, Okamura H, Todo M, Ikoma H, Kubota T, Nakanishi M, Kikuchi S, Okamoto K. PSK-mediated growth suppression and enhancement of 5-FU/docetaxel-induced cytotoxicity in human esophageal cancer cell lines. Gan To Kagaku Ryoho. 2009:36(12):1972-4

120. Zhang H, Morisaki T, Nakahara C, Matsunaga H, Sato N, Nagumo F, Tadano J, Katano M. PSK-mediated NF-kappaB inhibition augments docetaxel-induced apoptosis in human pancreatic cancer cells NOR-P1. Oncogene. 2003;22(14):2088-96.

121. Rosendahl AH, Sun C, Wu D, Andersson R. Polysaccharide-K (PSK) increases p21 (WAF/Cip1) and promotes apoptosis in pancreatic cancer cells. Pancreatology. 2012;12(6):467-74.

122. Liang HC, Tang H, Wei L. Effect of Ganoderma lucidum triterpenes on multi-drug resistance protein expression in ovarian cancer. Guangdong Med J. 2013;34(12):1829-31.

123. Yao X, Li G, XU H, Lü C. Inhibition of the JAK-STAT3 signaling pathway by ganoderic acid $A$ enhances chemosensitivity of $\mathrm{HepG} 2$ cells to cisplatin. Planta Med. 2012;78(16):1740-8.

124. Yue QX, Xie FB, Guan SH, Ma C, Yang M, Jiang BH, Liu X, Guo DA. Interaction of Ganoderma triterpenes with doxorubicin and proteomic characterization of the possible molecular targets of Ganoderma triterpenes. Cancer Sci. 2008;99(7):1461-70. 
125. Wang CC, Liang WB. Effect of Ganoderma lucidum polysaccharides on T cell subsets and AQP1, AQP3 expression of bladder cancer T24 cell line bearing mice. Chin J Biochem Pharm. 2016;36(12):33-6.

126. Sha CY, Shan FX. Improvement function of Ganoderma lucidum polysaccharides on T cell subsets and AQP1, AQP3 expression. Genom Appl Biol. 2018;37(1):16-22.

127. Liu B, Guo PR, Sheng YW, Fu DW. Effects of Ganoderma lucidum polysaccharide on chemotherapy effect and immune escape in T24 bearing mice. Cancer Res Prev Treat. 2015:42(5):459.

128. Wan JM, Sit W, Louie JC. Polysaccharopeptide enhances the anticancer activity of doxorubicin and etoposide on human breast cancer cells ZR-75-30. Int J Oncol. 2008;32(3):689-99.

129. Zhu X, Bao YX, Li J, Liu J, Wang HP. Anti-tumor effects and immunoregulatory activity of polysaccharopeptide from Yunzhi and tanshinone IIA in EAC tumor-bearing mice. Chin J Immunol. 2008;24(6):526-9.

130. Li J, Bao YX, Lam WK, Li WW, Lu F, Zhu X, Liu J, Wang HP. Immunoregulatory and anti-tumor effects of polysaccharopeptide and Astragalus polysaccharides on tumor-bearing mice. Immunopharmacol Immunotoxicol. 2008;30(4):771-82.

131. Kobayashi Y, Kariya K, Saigenji K, Nakamura K. Enhancement of anticancer activity of cisdiaminedichloroplatinum by the protein-bound polysaccharide of Coriolus versicolor QUEL (PS-K) in-vitro. Cancer Biother. 1994;9(4):351-8.

132. Zhang JY, Bi JC, Chu JZ. Prevention of white blood cell reduction in cancer patients on chemotherapy by Ganoderma lucidum. Chin J Inf Trad Chin Med. 2006;13(11):63

133. Wang YH, Qu ZH, Zhao ZY. Effect of Ganoderma lucidum spores on immune function in patients with non small cell lung cancer during chemotherapy. China Pract Med. 2014;23:20-1.

134. Lin ND, Su JN, Zhu Z, Gao YH, Gao H, Xie GY, Chen B, Ye XY. 66 case studies of cancer treatment with Ganoderma lucidum extract and chemotherapy. J Pract Trad Chin Intern Med. 2004;18(5):457-8.

135. Hattori T, Nakajima T, Nakazato $H$, Tanabe T, Kikuchi K, Abe O, Kondo T, Taguchi T, Komi N, Sugimachi K, Tominaga S. Postoperative adjuvant immunochemotherapy with mitomycin C, tegafur, PSK and/or OK-432 for gastric cancer, with special reference to the change in stimulation index after gastrectomy. Jpn J Surg. 1990;20(2):127-36.

136. Zhong Y, Zou J, Zhang LY. Clinical observation on alleviating chemotherapy's side effect of PSP in treating gastric carcinoma. Liaoning J Trad Chin Med. 2001;28(11):668-9.

137. Zhao Q, Chang Y, Pan J, Zhang JD. Effect of selenium-containing Yunzhi granules on immune function of breast cancer patients receiving chemotherapy after surgery. J Pharm Pract. 2004;22(3):156-7.

138. Yan AL, Ji SF. Effect of Yunzhi polysaccharides on immune function of breast cancer patients receiving chemotherapy after surgery. Acta Academiae Medicinae Suzhou. 1998;18(1): 14,37.

139. Shi JH, Chen T, Zhao RH, Sun YP, Lian ZR. Effect of PSP treatment during and between chemotherapy on immune function of stomach cancer after surgery. Chin J Clin Oncol Rehabil. 1996;3(2):3-4.

140. Zhang $\mathrm{H}$. Effect of polysacchario peptide on the immune function of patients with gastric carcinoma during operation and chemotherapy. China Med Herald. 2010;7(11):11-2.

141. Ke L, Yao PY, Gao ZM, Fan ST. An observation on the effects of polysaccharide peptide (PSP) as an accessary treatment for lung cancer. J Shanghai Normal Univ. (Natural Sciences). 1995;24(1):66-71.

142. Kikuchi Y, Kizawa I, Oomori K, Iwano I, Kita T, Kato K. Effects of PSK on Interleukin-2 production by peripheral lymphocytes of patients with advanced ovarian carcinoma during chemotherapy. Jpn J Cancer Res. 1988;79(1):125-30.

143. Gao F, Zhu YJ, Sun JG. Clinical observation of PSP with chemotherapy in treatment of non small cell lung cancer. J N China Coal Med College. 1999;1(5):436-7.

144. Shiu WCT, Leung TWT, Tao M. A clinical study of PSP on peripheral blood counts during chemotherapy. Phytother Res. 1992;6(4):217-8.

145. Wu XD, Zhang NH, He RK. Experimental study on Huolisu on adverse effects of chemotherapeutics. CJGMCM. 2017:22:3241-3.

146. Guo YJ, Wang QL, Yang XH, Jin CJ. Effect of "yiqi yangjing formula" on immunity function in lung cancer tumor-bearing Lewis mice and its mechanism. Acta Univ Trad Med Sin Pharmacol Shanghai. 2015;29(2):48-52
147. Hu ZL, Wen SG, Yu RJ, Zhu Y. Study of antitumor, increase efficacy and toxicity reduction function of Lingzhijun mixture. J Shandong Univ TCM. 2003:27(6):466-8.

148. Liu JY, Jin L, Jiang ZJ. Effect of Ganoderma lucidum spores oil on reducing the toxicity of radiochemotherapy and enhancing the function of immune system in mice. Lishizhen Med Mater Med Res. 2006;17(11):2179-81.

149. Zhou H, Sun F, Li H, Zhang S, Liu Z, Pei J, Liang C. Effect of recombinant Ganoderma lucidum immunoregulatory protein on cyclophosphamideinduced leukopenia in mice. Immunopharmacol Immunotoxicol. 2013;35(3):426-33.

150. Yu Q, Nie SP, Wang JQ, Liu XZ, Yin PF, Huang DF, Li WJ, Gong DM, Xie MY. Chemoprotective effects of Ganoderma atrum polysaccharide in cyclophosphamide-induced mice. Int J Biol Macromol. 2014;64:395-401.

151. Wang K, Wu G, Dai SM. Study on the immunological effect of the aqueous extract from Guangxi Ganoderma lucidum in the mice. J Guangxi Med Univ. 2003;20(6):871-4

152. Zhou GQ, Zhao HY, Lu C, Lu AP. Effect of Ganoderma lucidum polysaccharides on intestinal mucosal immune system in $\mathrm{H} 22$ liver cancer bearing mice. Chin J Integr Trad Western Med. 2009;29(4):335-9.

153. Jiang DW, Zhang J, He Y, Liu Q, Liu YM, Chen W, Wang QR, Li KX, Shen $X R$. Immune regulation effect of Ganoderma polysaccharide capsule on immunosuppressed mice. Med J Chin People's Liberat Army. 2016:41(9):719-24.

154. Liu BT, Wang P, Duan JC. Protective effects of Lingqihong capsule on hemopoietic system of mice. West China J Pharm Sci. 2007;22(4):402-4

155. Tang XH. Effect of Ganoderma lucidum decoction on immune function of mice. Trad Chin Med Res. 2000;13(6):8-10.

156. Zhu X, Chen A, Lin Z. Ganoderma lucidum polysaccharides enhance the function of immunological effector cells in immunosuppressed mice. J Ethnopharmacol. 2007;111(2):219-26.

157. Zhang HW, Xu YX, Yang XY, Li D, Seng CF, Wang Z. Protective effect of Ganoderma lucidum against adriamycin-induced cellular toxicity in rats. Acta Acad Med Shanghai. 1997;24(6):437-40.

158. Xing GQ, Nie HH, Qiu YF, Nie ZW. Influence of Ganoderma lucidum polysaccharide oral liquid on rats' immunization function. Chin Trad Patent Med. 2000;22(7):497-9.

159. Liu B, Guo PR, Sheng YW, Fu DW, Wang CC, Wang C. Effects of Ganoderma lucidum polysaccharides on peritoneal macrophages in nude mice bearing human bladder cancer T24 cells after chemotherapy and related immune mechanism. Chin Gen Pract. 2015;18(24):2971-5.

160. LiWD, Han Q Lin ZB. Study on effect of Ganoderma polysaccharide and lentinan in adjusting cyclophosphamide induced immunosuppression in tumor bearing mice. Chin J Integr Trad Western Med. 2001;21:101-2.

161. Sha RG, Zhang HB, Zhu XX. Experimental research on the effect of zhenzhiling granule on immunity in tumor bearing mice. Bull Chin Cancer. 2008:17(3):252-4

162. Chen L, Lin Z, Li W. Ganoderma lucidum polysaccharides reduce methotrexate-induced small intestinal damage in mice via induction of epithelial cell proliferation and migration. Acta Pharmacol Sin. 2011:32(12):1505-12

163. Wen ZB, Li JC, Xiong SL, He XF, He SL. Effects of resistance of Ganoderma japonicum (fr) lioyd mixture on side effects of cyclophosphamide on mice. J Human Coll TCM. 1997;17(2):44-6.

164. Liu GJ, Li J, Chen LL, Jiang ZJ, Liu PQ, Chen JW, Guo LB. The efficacy enhancing and toxicity reducing of Ganoderma lucidum spore oil emulsion to mice undergoing chemotherapy. Electron J Metab Nutr Cancer. 2017:4(1):60

165. Sun MF, Wei LZ, Xu DX, Wang JQ, Wang QN, Yu SZ. Experimental studies on antagonistic effects of spore of Ganoderma lucidum on side-effects induced by CP. China Public Health. 2001;17(6):509-10.

166. Li KX, Zhang HL, Zhu XP, Nie K, Guo W. Experimental studies of Phellinus linteus and Coriolus versicolor capsules on reducing adverse effect induced by chemotherapy. China J Exp Trad Med Form. 2009;15(4):64-5

167. Qian ZM, Xu MF, Tang PL. Polysaccharide peptide (PSP) restores immunosuppression induced by cyclophosphamide in rats. Am J Chin Med. 1997;25(1):27-35

168. Zhang J, Huang R, Liu Y, Wu C. Protective effects of PSP on immunosuppression mice induced by cyclophosphamide. J Liaoning Univ Trad Chin Med. 2013:15(07):47-50. 
169. Zhang J, Huang R, Hao YY, Liu Y, Wu C. Influence of polysaccharidepeptide of Coriolus versicolor on Th1/Th2 balance in the cyclophosphamide-induced immunosuppressive mice. Chin J Hosp Pharm. 2013;33(23):1922-5

170. Kono K, Kawaguchi Y, Mizukami Y, Mimura K, Sugai H, Akaike H, Fujii H. Protein-bound polysaccharide $\mathrm{K}$ partially prevents apoptosis of circulating $T$ cells induced by anti-cancer drug S-1 in patients with gastric cancer. Oncology. 2008;74(3-4):143-9.

171. Wu P, Huang R, Zhang J, Liu R, Xiong YL, Yang CC, Wu C. Influence of polysaccharopeptide on mRNA expressions of Foxp3, PD-1 and IL-10 in spleen of immunosuppressive mice. Jiangsu Med J. 2015;41(13):1502-4.

172. Torigoe K. Sister chromatid exchanges in children treated with azathioprine and cyclophosphamide, and effect of protein-bound polysaccharide (PS-K). Jpn J Hum Genet. 1980;25(1):15-21.

173. Kashimoto $N$, Ishii S, Myojin $Y$, Ushijima M, Hayama M, Watanabe H. A water-soluble extract from cultured medium of Ganoderma lucidum (reishi) mycelia attenuates the small intestinal injury induced by anticancer drugs. Oncol Lett. 2010;1(1):63-8.

174. Wang L, Chen J, Yang HM, Pei R, He GZ. Experimental study of treatment with Ganoderma lucidum polysaccharides and cisplatin in tumorbearing mice. China J Chin Mater Med. 2005;30(11):874-5.

175. Wang L, Chen J, Pei R, Yang HM, Chen XL, Gui XF. Effects of Ganoderma lucidum polysaccharide pretreatment on nephrotoxicity induced by cisplatin and carcinoma inhibition rate. J Henan Med Coll Staff Work. 2004;16(3):212-4

176. Gui XF, Wang L, Chen XL, Yang YH, Fei R, Ma XF, Yang HM. Experimental study on lucid Ganoderma injection in preventing cis-platinum nephrotoxic. Henan Trad Chin Med. 1998;18(5):281-2.

177. Gui XF, Wang L, Chen XL, Yang YH, Fei R, Ma XF, Wang SZ. Experimental study on Ganoderma lucidum injection in reduction of cisplatin toxicity. Chin J Integr Trad Western Med. 1999:19:76-7.

178. Pillai TG, John M, Sara Thomas G. Prevention of cisplatin induced nephrotoxicity by terpenes isolated from Ganoderma lucidum occurring in southern parts of India. Exp Toxicol Pathol. 2011;63(1-2):157-60.

179. Liu YX, Yan Y, Wang B, Chen YY, Ji W, Du JR. Antitumor activity of Cornu cervi Ganoderma lucidum capsule and protective effect on cisplatin induced kidney damage. West China J Pharm Sci. 2008;23(5):564-6.

180. Wang L, Yang HM, Chen J, Pei R, Gui XF. Experimental study of Ganoderma lucidum polysaccharide against kidney damage induced by cisplatin in rats. Chin Trad Patent Med. 2003;25(12):990-3.

181. Rajasekaran M, Kalaimagal C. Cardioprotective effect of a medicinal mushroom, Ganoderma lucidum against adriamycin induced toxicity. Int J Pharmacol. 2012;8:252-8.

182. Xu F, Li X, Liu LF, Pan XH, Zhang L, Zhang SL, Lin PP, Li QS. Protective effects of Ganoderma lucidum polysaccharides on adriamycin-induced myocardial injury. Chin J Control Endemic Disenaces. 2017:32(4):372-5.

183. Yan Y, Bai WZ, Wang LA, Pei L, Yang J, Ma YQ, Li HG. Inhibitory effects of Ganoderma lucidum polysaccharides on cisplatin-induced vomit. Mycosystema. 2009;3:456-62.

184. Wang CZ, Basila D, Aung HH, Mehendale SR, Chang WT, McEntee E, Guan X, Yuan CS. Effects of Ganoderma lucidum extract on chemotherapy-induced nausea and vomiting in a rat model. Am J Chin Med. 2005;33(5):807-15.

185. Cui WM, Liu ZQ, Wang W, Zhang Q, Li N, Han C. Study on antimutagenic effect of the aqueous extract of Ganoderma lucidum. Chin J Food Hyg. 2002;14(5):11-3.

186. Zhang W, Zeng YS, Xiong Y, Tang JY, Chen SJ, Zhong ZQ. Effects of Ganoderma spores on CDK4 expression in preventing embryonic neural tube defects induced by retinoic acid in pregnant mice. Anat Res. 2006:28(4):251-3.

187. Ma GJ, Xue KX, Wu JZ, Shen ZL, Chen SQ. Inhibitory effects of compound Coriolus capsules on MMC-induced mutation and spontaneous mutation in old donors. Shanxi Med J. 1999;28(1):20-1.

188. Hasegawa J, Hosokawa M, Okada F, Kobayashi H. Inhibition of mitomycin C-induced sister-chromatid exchanges in mouse bone marrow cells by the immunopotentiators Krestin and lentinan. Mutat Res. 1989;226(1):9-12.

189. Yokoyama C, Sueyoshi Y, Ema M, Mori Y, Takaishi K, Hisatomi H. Induction of oxidative stress by anticancer drugs in the presence and absence of cells. Oncol Lett. 2017;14(5):6066-70.

190. Wang L, Fei R, Yang HM, Chen J. Inhibition on cisplatin-induced oxidative stress in blood by Ganoderma lucidum polysaccharides. Chin J Public Health. 2004;20(9):1091-2.

191. Gui XF, Wang L, Yang YH, Chen XL, Fei R, Ma XF, Yang HM. Effect of Ganoderma lucidum injection and cisplatin on blood and renal SOD and MDA level in tumor-bearing mice. TCM Res. 1993;1:31-3.

192. Gui XF, Wang L, Chen XL, Yang YH, Fei R. Experimental study of protec tion of renal cortical cell through free radical removal by Ganoderma lucidum injection. Chin J Biochem Pharm. 1996;17(5):188-9.

193. Coriolus Mushroom. In: natural medicines [database on the Internet]. Somerville (MA): therapeutic research center; 2020. https://naturalmed icines.therapeuticresearch.com. Accessed 27 June 2020

194. Li X, Yang G, Li X, Zhang Y, Yang J, Chang J, Sun X, Zhou X, Guo Y, Xu $Y$, Liu J, Bensoussan A. Traditional Chinese medicine in cancer care: a review of controlled clinical studies published in Chinese. PLOS ONE. 2013;8(4):e60338.

195. Cheng CW, Wu TX, Shang HC, Li YP, Altman DG, Moher D, Bian ZX. CONSORT extension for Chinese herbal medicine formulas 2017 : recommendations, explanation, and elaboration. Ann Intern Med. 2017;167(2):112-21.

196. Dai L, Cheng CW, Tian R, Zhong LL, Li YP, Lyu AP, Chan AW, Shang HC, Bian ZX. Standard protocol items for clinical trials with traditional Chinese medicine 2018: recommendations, explanation and elaboration (SPIRIT-TCM Extension 2018). Chin J Integr Med. 2019;25(1):71-9.

\section{Publisher's Note}

Springer Nature remains neutral with regard to jurisdictional claims in published maps and institutional affiliations.

Ready to submit your research? Choose BMC and benefit from

- fast, convenient online submission

- thorough peer review by experienced researchers in your field

- rapid publication on acceptance

- support for research data, including large and complex data types

- gold Open Access which fosters wider collaboration and increased citations

- maximum visibility for your research: over 100M website views per year

At $\mathrm{BMC}$, research is always in progress.

Learn more biomedcentral.com/submissions 